\title{
Body size, energy consumption and allometric scaling: a new dimension in the diversity-stability debate
}

\author{
Anastassia M. Makarieva ${ }^{a, b, *}$, Victor G. Gorshkov ${ }^{a}$, Bai-Lian Li ${ }^{b}$ \\ ${ }^{a}$ Theoretical Physics Division, Petersburg Nuclear Physics Institute, Gatchina, St. Petersburg 188300, Russia \\ ${ }^{\mathrm{b}}$ Ecological Complexity and Modelling Laboratory, Department of Botany and Plant Sciences, \\ University of California, Riverside, CA 92521, USA
}

Received 22 September 2003; received in revised form 11 January 2004; accepted 20 February 2004

\begin{abstract}
A new theoretical approach is developed that links the allometry of energy partitioning among differently-sized organisms in ecological community to community stability. The magnitude of fluctuations of plant biomass introduced by plant-feeding heterotrophs is shown to grow rapidly with increasing body size. To keep these fluctuations at a low level compatible with ecosystem stability, the share of ecosystem primary productivity claimed by plant-feeding heterotrophs should decrease with increasing body size. In unstable environments the ecological restrictions on biotic fluctuations are lessened and net primary productivity can be distributed more evenly among differently sized organisms. Within the developed approach it is possible to quantitatively estimate not only the scaling exponents in the dependence of population density and biomass of heterotrophs on body size, but also the absolute values of energy fluxes claimed by organisms of a given size in stable communities. Theoretical predictions are tested against diverse sets of empirical data. It is shown that in stable ecological communities the largest heterotrophs are allowed to consume no more than several tenths of percent of net primary productivity.
\end{abstract}

(C) 2004 Elsevier B.V. All rights reserved.

Keywords: Allometric scaling; Biomass; Biosphere; Body size; Boreal forests; Disturbance; Diversity-stability debate; Ecological community; Energy consumption; Fluctuations; Forest succession; Herbivores; Mammals; Metabolic rate; Population density; Primary productivity

\section{Introduction}

Size is probably the single most obvious feature of an organism, and it profoundly affects structure and function. On average, larger organisms have higher metabolic rate $R$ but lower population density $D$ than

\footnotetext{
* Corresponding author. Tel.: +7-812-7131963; Fax: +7-812-7131963.

E-mail address: elba@infopro.spb.su (A.M. Makarieva).
}

smaller ones. The dependencies of $R$ and $D$ on body size determine the pattern of energy partitioning within the ecological community, i.e., whether the cumulative energy flux claimed by the larger organisms is lower, equal to, or higher than that of the smaller ones. The importance of this question for understanding the principles of organisation of natural ecological communities explains the incessant interest the scientific community shows in this problem over last several decades. 
Damuth $(1981,1987)$ pointed out that in mammals and several other higher taxa $D$ decreases proportionally to $M^{-0.75}$, where $M$ is body mass. Assuming that metabolic rate $R$ increases as $M^{0.75}$ (Kleiber, 1932; Hemmingsen, 1960; Nagy, 1987), Damuth put forward the idea of energetic equivalence of species, i.e., that every species consumes the same amount of energy per unit time per unit area irrespective of its body size. This result has been widely discussed and tested against different types of data (Peters and Wassenberg, 1983; Brown and Maurer, 1986; Robinson and Redford, 1986; Lawton, 1990; Marquet et al., 1990; Nee et al., 1991; Blackburn et al., 1993; Damuth, 1993; Greenwood et al., 1996; Navarrete and Menge, 1997; Knouft, 2002). Scaling exponents both similar to Damuth's -0.75 and significantly different from it were found. The employed methods of data analysis were also subjected to close scrutiny, in particular the methods of determining population density (Blackburn et al., 1990; Blackburn and Gaston, 1996) and statistical methods used to estimate the scaling exponents in the $D-M$ relationship (LaBarbera, 1989; Griffiths, 1992).

An additional problem raised was that the number of species in the ecological community is also a function of body size (see, e.g., Harvey and Lawton, 1986; Brown and Nicoletto, 1991). There are, for example, more rodent than ungulate species. If each species consumes equal amount of energy, the cumulative energy consumption of the smaller organisms will be higher than that of the larger ones. Studies of aquatic communities traditionally operating with size-class rather than species population density are on average characterised by $D-M$ scaling exponents clustering around -1 rather than around -0.75 (Sprules and Munawar, 1986; Gaedke, 1993; Griffiths, 1992; Cohen et al., 2003). This pattern, often referred to as the biomass equivalence rule (Damuth, 1994; Polishchuk, 1994), $B \equiv D M \propto M^{0}$, is also supported by studies of soil animals over a wide range of body sizes (Ghilarov, 1967). On the other hand, size-class biomass of other animals, e.g., tropical arthropods (Stork and Blackburn, 1993) or microscopic soil organisms (Lin and Brookes, 1999), was shown to grow conspicuously with body size.

In the view of the substantial uncertainty that is associated with the scaling exponents of the $D-M$ and $B-M$ relationships, as well as with the dependence of species number on body size (e.g., global versus local patterns, see Brown and Nicoletto, 1991), one has to conclude that so far there is no general answer to the question of whether the larger organisms consume greater or smaller portions of the community's energy flux than the smaller ones.

A different but equally hot focus of attention in modern ecological studies is the problem of ecosystem stability (McCann, 2000; Ernest and Brown, 2001; Li and Charnov, 2001; Yamamura, 2002). It acquires a glaring importance in the view of the increasing anthropogenic pressure imposed on natural ecosystems. A critical variable in the ecosystem stability studies is the number of species. There is a lively debate on whether more diverse (having more species) ecological communities are more or less stable than less diverse ones, and whether the diversity is the cause or consequence of stability (reviewed in McCann, 2000). The species body size and the share of community's energy flux allocated to differently sized organisms are at best marginal parameters or completely absent from the numerous models developed for the study of ecosystem stability (Leigh, 1965; DeAngelis, 1980; Moore et al., 1993).

In this paper we aim to show that the theoretical problem of energy partitioning over differently sized organisms is central to the ecosystem stability problem, and vice versa. We propose that natural ecological communities are organised in a way maximising their stability and minimising the fluctuations of all life-important environmental parameters, including nutrient concentrations and live biomass.

To meet their energy requirements, large organisms have to move over extensive areas exempting large amounts of locally accumulated plant biomass. By doing so, they introduce spatial and temporal fluctuations of organic matter, as well as of inorganic nutrients that concentrate in the excreta. The magnitude of such biotically induced fluctuations grows rapidly with increasing body size. We show that in order to keep environmental fluctuations at a level compatible with ecosystem stability, the share of energy consumption allocated to the larger heterotrophs in stable ecosystems should be suppressed, i.e., it should decrease with increasing body size.

By imposing restrictions on fluctuations of plant biomass introduced by plant-feeding heterotrophs of 
a given body size we derive quantitative predictions of how population density and energy consumption of plant-feeding heterotrophs is dependent on body size. We test the theoretical predictions with the available empirical data (a brief outline of the evidence presented in this paper was given by $\mathrm{Li}$ et al. (2004)). Distinctive from the earlier studies, our theoretical approach allows us to quantify not only the scaling exponents of the $D-M$ and related allometric dependencies, but also the absolute values of the corresponding variables. We show that in stable natural ecological communities the largest heterotrophs are allowed to consume no more than several tenths of per cent of the ecosystem's net primary productivity.

Some ecological communities exist in unstable, highly fluctuating environments shaped by physical matter fluxes that are more powerful than community's productivity. In such cases the magnitude of environmental fluctuations is determined by factors uncontrollable by the local biota. The ecological restrictions on environmental fluctuations introduced by larger heterotrophs appear to be lessened-it is no use to keep the biotically induced fluctuations low if the abiotic ones are high anyway.

As a result, in unstable ecosystems the allometric distribution of energy consumption over body size flattens, and the larger animals can claim energy fluxes comparable to those of smaller ones. The more unstable the ecosystem, the more irregular and flatter the distribution of energy consumption over body size. We argue that current neglect of the degree of environmental stability is the major obstacle to revealing general regularities in the allometry of energy partitioning in the different types of ecosystems studied.

We propose that the distribution of energy consumption over body size of heterotrophs is a critical indicator of ecosystem stability. Stable ecological communities can be composed of a minimal number of species provided these species feature a small body size. Such ecological communities can be exemplified by epilithic lichens consisting of one algae and one fungi species (Farrar, 1976). On the other hand, no ecological community is expected to be stable if the most part of community's energy is consumed by large heterotrophs, independent of the community's species richness. We outline the ways of how the developed theoretical approach could be used in nature conservation practices and in the global-scale analysis of biospheric stability.

\section{General approach}

The characteristic time scale of a biotically induced environmental change is remarkably short. The photosynthetic power of plants is such that the global stores of life-important inorganic substances can be used up completely in about ten years. For example, the amount of $\mathrm{CO}_{2}$ in the atmosphere is of the order of $10^{12} \mathrm{tC}$, while the productivity of the global biota is of the order of $10^{11} \mathrm{tC}$ per year (Lieth, 1975).

The stability of ecological community can be characterised by the smallness of fluctuations of the standing stores of organic and inorganic nutrients. These fluctuations arise due to the fact that, being performed by different organisms, the processes of synthesis and decomposition of organic matter do not compensate each other precisely at all times. If the flux of decomposition exceeds the flux of synthesis, there appears a risk of complete devastation of the local store of organic matter, including live biomass of the primary producers (plants). If the flux of synthesis significantly exceeds the flux of decomposition, there appears an environmental deficit of inorganic biogens (nitrogen, phosphorus, etc.). Such a deficit undermines the process of photosynthesis and can also lead to degradation of the primary producers and, ultimately, of the entire ecological community. Given the nearly instantaneous time scale of such potential unfavourable outcomes, it is natural to expect that in the course of evolution the minimisation of fluctuations of the major environmental components has become the major principle of organisation of natural ecological communities.

Plants form the basis of community's energetics. They are responsible for the synthesis of organic matter, which further fuels all life processes in the community. To make this flux stable, the photosynthesising parts of plants dominating natural terrestrial ecosystems represent a large number of weakly correlated objects of relatively small size (e.g., leaves, needles). The fluctuations of phytomass of individual plant are thus minimised in accordance with the statistical law of large numbers (see Appendix A). For 
example, an adult fir tree Larix gmelinii has several million needles, $N_{1} \sim 10^{6}$, that fall off and re-grow every year (Kajimoto et al., 1999). Thus, the yearly relative fluctuation of individual plant's phytomass (when detrended against non-random processes like tree growth) does not exceed $\varepsilon_{1} \sim 1 / \sqrt{N_{1}} \sim 10^{-3}$, i.e., $0.1 \%$. The same figure approximately characterises yearly fluctuation of primary productivity.

Clearly, low values of relative fluctuations $\varepsilon_{1}$ of phytomass and primary productivity could have only evolved and been further maintained in the course of competitive interaction of individual plants with different $\varepsilon_{1}$ values-plants demonstrating the inability to stabilise their phytomass and productivity at a needed value were losing to those that did so. A detailed discussion of characteristic $\varepsilon_{1}$ values can be found in Section 6.

It would not be advantageous for a plant to keep the process of photosynthesis stable and fluctuations $\varepsilon_{1}$ of the phytomass minimised, unless the fluctuations of plant biomass introduced by the process of decomposition are equally low. In other words, a plant providing food to heterotrophs who consume it in an erratic fashion would be equally suffering from biomass fluctuations as compared to a plant with unstable photosynthesis. Hence, it is justified to expect that fluctuations of plant biomass introduced by its consumption by heterotrophs do not normally exceed the fluctuations $\varepsilon_{1}$ introduced by the process of photosynthesis.

Whilst photosynthesis is performed by objects of similar size (e.g., needles), the decomposition of the produced organic matter is performed by organisms with linear size varying from several micrometers (bacteria) to meters (large mammals). In the following section, we aim to show that body size is a major determinant of the magnitude of plant biomass fluctuations that are introduced by heterotrophic organisms.

As long as conversion of plant to animal biomass occurs at a relatively low efficiency of the order of $10 \%$ (Odum, 1971), the major energy flow within the ecosystem can be estimated at the bottom of the ecological pyramid, i.e., by estimating energy consumption by plant-feeding heterotrophs. Everywhere below we confine our consideration to plant-feeding organisms, i.e., those decomposing the organic matter of plants in either dead or living form. We define organism as a plant-feeding if plant biomass comprises not less than $50 \%$ of its diet.

\section{Fluctuations of consumption due to locomotion of heterotrophs}

While moving over a given territory, animals bring about local fluctuations of plant biomass. Interaction of the animal with plant biomass can be represented as a series of discrete acts of food intake.

The space scale of a single act of food intake is determined by the area of the food-gathering organ of the animal, e.g., mouth, hand, and trunk (of elephant). This area can be described as $\delta l^{2}$, where $l$ is the linear body size and $\delta$ is a small dimensionless coefficient. For example, the palmar surface of an adult human is about $60 \mathrm{~cm}^{2}$, which is about $\delta \sim 0.04$ of the total body surface. (Everywhere in this paper we define linear body size $l$ as $l \equiv(M / \rho)^{1 / 3}$, where $M$ is body mass and $\rho$ is the density of living matter taken to be approximately equal to that of water, $\rho \sim 1 \mathrm{~g} \mathrm{~cm}^{-3}$. Body surface is defined as $(M / \rho)^{2 / 3}$. Where we need to operate with apparent linear body size $l_{\mathrm{a}}$ (e.g., vent to snout length), this will be explicitly stated). Characteristic values of $\delta$ are discussed in Section 6.

The amount of plant biomass exempted by the animal during one act of food intake (one bite in ungulates, one grasp in primates, etc.) can be written as

$f=B_{1} \delta l^{2}$,

where $B_{1}$ is the edible (metabolically active) plant biomass per unit area (see Appendix A). We note that Eq. (1) is valid for sufficiently large heterotrophs (e.g., mammals) that are able to consume all or a significant part of plant biomass present on the area $\delta l^{2}$. Smaller animals (e.g., insects) will be considered separately in Section 5.4. The numeric validity of Eq. (1) is tested in Section 6. For the present we note that the scaling $f \propto$ $M^{2 / 3}$ implied by Eq. (1) agrees very well with available data on maximum bite size in mammalian herbivores, which scales as $M^{0.71}$ (Shipley et al., 1994).

Let us now introduce area $s_{1}$ occupied by a single individual of a dominant plant species. In forest ecosystems $s_{1}$ is equal to the projection area of a single tree's crown. As was shown by Karpov (1983) and colleagues in their work on interspecific interactions in spruce forests, the dominant tree species controls species composition and population density of the under-canopy vegetation by means of regulating local environmental parameters, in particular-soil composition, favourable for some and unfavourable for oth- 
ers under-canopy species. There is a tight correlation between root-mycorrhiza systems of dominant trees and under-canopy vegetation, which facilitates mutually beneficial sharing of both inorganic and organic nutrients among tree and the smaller under-canopy plants (Lerat et al., 2002). Dominant plants create and maintain the chemical composition of soil and dictate its spatial organisation (Hook et al., 1991; Smith, 1996; Rhoades, 1997; Døckersmith et al., 1999). Spatial distribution of the smallest heterotrophs, bacteria and mycorrhizal fungi, is autocorrelated around individual trees (Pennanen et al., 1999). This allows the tree to close biochemical cycles on a local scale supporting soil fertility (Heinonsalo et al., 2001). It is natural therefore to consider an individual tree, the associated under-canopy vegetation and the local heterotrophic biota as an elementary ecosystem unit. The characteristic scale $s_{1}$ thus acquires fundamental ecological importance.

There are organisms that can be called residents of a single ecosystem unit (their home range $S$ is less than $s_{1}, S<s_{1}$ ). Through all their life such organisms may move within one and the same canopy or within root system of one and the same tree. All plant biomass consumed by such residents on area $s_{1}$ will be decomposed within the same area. All inorganic nutrients will thus be returned to the ecosystem unit to be recycled by the same tree.

Animals with home range significantly exceeding $s_{1}, S \gg s_{1}$, can be called travellers. While moving over their feeding territory, they exempt plant biomass from different ecosystem units. For example, an ungulate Moschus moschiferus, an inhabitant of coniferous mountainous forests of Siberia, feeds on needles moving from one tree to another. Smaller species like rodents feed on under-canopy vegetation under different trees (Fig. 1).

If the biological design of the animal is such that its metabolic rate $R$ is relatively stable, the consumption of plant biomass by the resident within one and the same ecosystem unit will be equally stable. The traveller moves over a large territory $S$. Although its metabolic rate $R$ can be the same stable as that of the resident, the exemption of plant biomass by the traveller from particular ecosystem units will nevertheless undergo significant fluctuations. Moving randomly over the feeding territory, the animal may eat more in one ecosystem unit and less in the other (Fig. 1).

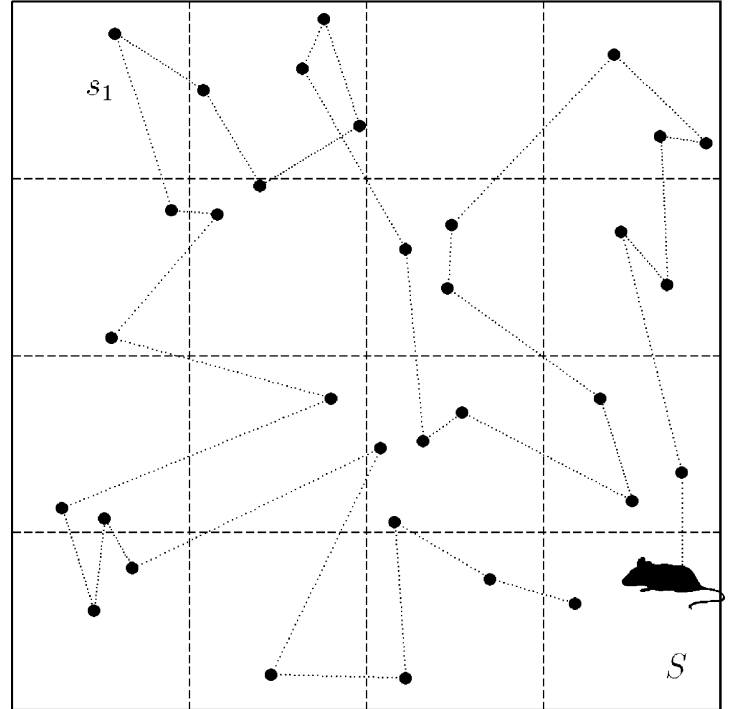

Fig. 1. Distribution of discrete acts of food intake (circles) over different ecosystem units (squares of area $s_{1}$ ) composing the home range (large square of area $S$ ) of a plant-feeding heterotroph (mouse). Dashed lines denote borders of adjacent ecosystem units, dotted lines describe a presumable trajectory of movement of the animal.

We now express this idea quantitatively. In the formulas to follow the variables plant biomass $B_{1}$, net primary productivity $P_{1}$ and metabolic rate $R$ can be expressed all either in mass units $\left(B_{1}, \mathrm{kgC} \mathrm{m}^{-2} ; P_{1}\right.$, $\mathrm{kgC}$ per $\mathrm{m}^{2}$ per year ${ }^{2} ; R, \mathrm{kgC}$ per individual per year) or in energetic units $\left(B_{1}, \mathrm{~J} \mathrm{~m}^{-2} ; P_{1}, \mathrm{~W} \mathrm{~m}^{-2}\right.$; $R, \mathrm{~W}$ per individual). The conversion coefficient from mass to energetic units is determined by the energy content of organic carbon, which is on average $K=$ $42 \times 10^{3} \mathrm{~J}(\mathrm{~g} \mathrm{C})^{-1}$ (Brody, 1945; Odum, 1971).

We consider the time scale equal to the turnover (regeneration) time of metabolically active plant biomass, $\tau_{1} \equiv B_{1} / P_{1}$, where $P_{1}$ is the ecosystem's primary productivity. During time $\tau_{1}$ the organism consumes $R \tau_{1}$ $\mathrm{kg}$ of plant carbon making $N=R \tau_{1} / f$ acts of food intake, see Eq. (1). These are distributed randomly over the home range area $S$ of the animals. The number $n_{i}$ of acts of food intake made within the $i$-th ecosystem unit is therefore a random variable (Fig. 1).

We now introduce a related random variable $\beta_{i}$, which is equal to the share of net primary productivity consumed by the animal in the $i$-th ecosystem unit. Net primary production on $s_{1}$ during time $\tau_{1}$ is $P_{1} s_{1} \tau_{1}$, 
while the consumed plant biomass is $n_{i} f$, so that $\beta_{i} \equiv$ $n_{i} f / P_{1} s_{1} \tau_{1}=n_{i} f / B_{1} s_{1}$. Using Eq. (1) we thus have

$n_{i}=\beta_{i} \frac{s_{1}}{\delta l^{2}}, \quad n=\beta \frac{s_{1}}{\delta l^{2}}$

$N=\frac{R \tau_{1}}{f}=\beta \frac{S}{\delta l^{2}}, \quad \beta=\frac{R}{P_{1} S}$.

Here $\beta$ is the mean share of net primary productivity consumed by one organism, $n$ is the mean of $n_{i}$.

In Fig. 1 the parameter $N$ corresponds to the total number of circles in the large square $S$, while the random variable $n_{i}$ corresponds to the number of circles in any small square $s_{1}$. Under the assumption that consumption of biomass by the animal is equally probable at any point of its home range $S$, the number $n_{i}$ is distributed among local areas $s_{1}$ in accordance with the binomial distribution (see Appendix B). The mean $n$ and variance $\sigma_{n}^{2}$ of the random number $n_{i}$ of food intake acts on area $s_{1}$ are

$n=N \frac{s_{1}}{S}, \quad$ and $\quad \sigma_{n}^{2}=n\left(1-\frac{s_{1}}{S}\right)$.

If $S=s_{1}$, the organism remains within one and the same ecosystem unit. As is clear from (4), the fluctuations of biomass consumption related to moving across different ecosystem units are zeroed. Organisms with $s_{1} \geq S$ are residents with suppressed fluctuations of consumption.

The organisms with $S>s_{1}$ are travellers. At $s_{1} \ll$ $S$ (which is the case for most mammals, for example), the binomial distribution turns to Poisson distribution, for which, as is well-known, the mean is simply equal to variance, $n=\sigma_{n}^{2}$ (see Appendix $\mathrm{B}$ ). The mean amount of biomass consumed by the animal on area $s_{1}$ equals $n f$, while its variance equals $\sigma_{n}^{2} f^{2}=n f^{2}$. The squared relative fluctuation $\varepsilon^{2}$ of plant biomass on area $s_{1}$ due to consumption by the considered animal becomes

$\varepsilon^{2}=\frac{n f^{2}}{\left(s_{1} B_{1}\right)^{2}}$.

Here $s_{1} B_{1}$ is the total amount of plant biomass on area $s_{1}$. Variable $\varepsilon$ describes the difference between the amounts of plant biomass remaining in different ecosystem units after a random number $n_{i}$ acts of food consumption the animal performs in each of them. Putting relation (2) for $n$ into Eq. (5), we obtain the following expression for the share of energy consumption $\beta$ of the considered animal:

$\beta=\frac{\varepsilon^{2} s_{1}}{\delta l^{2}}$.

It is clear from Eq. (6) that if the share of consumption of plant biomass remained independent of body size $l$, the relative fluctuation $\varepsilon$ of plant biomass introduced by the heterotroph would increase proportionally to body size $l$. As we show below, the minimum body size of heterotrophs-travellers is of the order of $10^{-4} \mathrm{~m}$ (flying insects), while the maximum is of the order of $1 \mathrm{~m}$. Thus, in the course of evolutionary increase of body size the fluctuations of biomass would increase by approximately $10^{4}$, if no restrictions were imposed on $\beta$.

The real ecological communities include more than one species of highly mobile heterotrophs. These species may feature either similar or different body sizes $l$. In such a case the sum of squares of relative fluctuations introduced by all heterotrophic species feeding on a local territory $s_{1}$ in the community should not exceed $\varepsilon_{1}^{2}, \sum_{i} \varepsilon_{i}^{2} \leq \varepsilon_{1}^{2}$, where summation is over all species feeding on $s_{1}$.

As follows from Eq. (6), the share of energy consumption $\beta$ and relative fluctuation of plant biomass introduced by highly mobile animals is independent of metabolic rate $R$ and would be the same for endothermic and exothermic organisms. The magnitude of $\varepsilon^{2}$ and $\beta$ is determined by the total amount of animals of a given body size, independent of whether they are conspecific or belong to different species. Body size $l$ appears as the single variable controlling both $\varepsilon^{2}$ and $\beta$.

To account for the change of body size $l$ we introduce the linear spectral density of the share of energy consumption and squared relative biomass fluctuation:

$\beta_{l} \equiv \frac{1}{\Delta l} \sum_{l}^{l+\Delta l} \beta, \quad \varepsilon_{l}^{2} \equiv \frac{1}{\Delta l} \sum_{l}^{l+\Delta l} \varepsilon^{2}$,

where summation is made over all heterotrophic individuals with body size confined between $l$ and $l+\Delta l$.

The condition that fluctuations introduced by highly mobile heterotrophs of all body sizes, from minimum $l_{\min }$ to maximum $l_{\max }$ in total do not exceed the fluc- 
tuations of plant biomass introduced by plants themselves (Appendix A), thus assumes the form:

$\int_{l_{\min }}^{l_{\max }} \varepsilon_{l}^{2} \mathrm{~d} l \leq \varepsilon_{1}^{2}$.

Eq. (8) takes into account that consumption of plant biomass by heterotrophs from different body-size intervals is uncorrelated, so that the square of the cumulative fluctuation is equal to the sum of squares of fluctuations from each body-size interval.

Generally speaking, the spectral density of squared relative fluctuation $\varepsilon_{l}^{2}$ in Eq. (7) can be an arbitrary function of body size $l$. Here we make a reasonable assumption that the fluctuations do not grow with body size, so that heterotrophs from any equal body size interval make equal contributions into the cumulative biomass fluctuation, i.e., that $\varepsilon_{l}^{2}=$ const. In such a case taking into account that $l_{\max } \gg l_{\min }$ we have from Eq. (7):

$\varepsilon^{2}=\frac{\varepsilon_{1}^{2}}{l_{\max }}$.

For the linear spectral density of the share of energy consumption $\beta_{l}$, Eq. (7), we have from Eqs. (6), (7) and (9):

$\beta_{l}=\frac{\varepsilon_{1}^{2} s_{1}}{l_{\max } \delta l^{2}}$.

The linear spectral density $\beta_{l}$ has the dimension of inverse length. It is not convenient for the quantitative analysis of the available empirical data, which usually refer to logarithmic intervals of body size. The transition from linear $\beta_{l}$ to logarithmic $\beta(l)$ spectral density of the share of energy consumption can be performed as

$\beta(l) \equiv \int_{l}^{k l} \beta_{l} d l$,

where $k$ is the base of the logarithm used. For example, if the studied interval of body size is from 1 to $10 \mathrm{~cm}$ (linear size), then we have $k=10$. If the studied interval is from 1 to $10 \mathrm{~g}$ (body mass), we have $k=$ $\sqrt[3]{10}=2.15$, as far as a tenfold increase in body mass corresponds to a 2.15 -fold increase of linear size $l$.

From Eqs. (10) and (11) we have

$\beta(l)=\left(1-\frac{1}{k}\right) \frac{1}{l} \frac{\varepsilon_{1}^{2} s_{1}}{l_{\max } \delta}$.
The share of net primary productivity consumed by highly mobile heterotrophs (travellers) from a unit logarithmic interval of body size decreases inversely proportionally to linear body size $l$, i.e., proportionally to $M^{-1 / 3}$.

For population density $D(l)$ and biomass $B(l)$ of highly mobile heterotrophs from logarithmic body size intervals we have

$D(l)=\frac{\beta}{R} P_{1} \propto \frac{1}{l R}$.
$B(l)=D M \propto \frac{M}{l R}$.

As long as $R \propto M^{\alpha}$, where the value of $\alpha$ is normally not less than $2 / 3$, Eq. (14) suggests either a constant biomass $B \propto M^{0}$ (if $\alpha=2 / 3$, as is the case in birds, for example (Nagy, 1987; Dodds et al., 2001)) or a decrease of biomass at a rate of $B \propto M^{1-(1 / 3+\alpha)}$ (if $\alpha>2 / 3$ ).

\section{Stable versus unstable ecological communities}

The basis for the theoretical predictions formalised by Eqs. (12)-(14) is formed by the idea that elementary ecosystem units (e.g., in forest ecosystems these were defined by us as trees with the attached local biota) are organised so as to minimise fluctuations of all life-important environmental characteristics. Plant biomass is responsible for the primary flux of energy in the ecosystem, which drives the local biogeochemical cycles of all nutrients. Hence, fluctuations of plant biomass due to its consumption by plant-feeding animals lead to fluctuations of local fluxes and stores of organic and inorganic nutrients. The plant biomass fluctuations introduced by individual animals grow rapidly with increasing body size. For the stability of the ecosystem unit's functioning to be conserved, the absolute amount of primary productivity allocated to large heterotrophs should decrease with increasing body size.

Such a principle of community organisation is only meaningful if the abiotic fluctuations of the community's environment are small. This is the case when the abiotic processes fluxes of matter for environmental fluctuations are less powerful than the biological fluxes of synthesis and decomposition. For example, although the chemical composition of forest 
soil is always under disturbing pressure of water and wind erosion, the power of biological productivity of trees is high enough to compensate for such disturbances and stabilise the soil composition in forests (Lal, 1990).

The share of energy consumption allocated to plant-feeding heterotrophs of different body sizes is determined by plants themselves. Plant phytomass can vary greatly in such properties like toughness, toxicity, nutrition value etc. that were shown to directly regulate the rate of herbivory (Coley and Barone, 1996; Haukioja and Koricheva, 2000). The phenology of foliage development (e.g., shifting leaf production to peak during the time of year when the abundance of herbivores is lowest) is another major control of the consumption rates. On the community's level, many plants are able to produce attractants for the natural enemies of their herbivores (e.g., ants) (see Coley and Barone (1996) and references therein). More advanced means of regulation of the population density and consumption rates of plant-feeding heterotrophs by plants can presumably include control of the amount of habitable surfaces (like leaf area for arthropods) (Morse et al., 1985) or spatial distribution of concentrated food resources (Haskell et al., 2002).

Since the controlling characteristics of plants apparently have a genetic basis, it is clear that they evolved in the course of natural selection of plants composing ecosystem units. Those ecosystem units where animals of a given size were allowed to consume a strictly specified amount of plant biomass, cf. Eq. (12), enjoyed a stable and favourable environment. Plants from such units won over plants that could not ensure a stabilised consumption. As a result, the needed plant properties leading to stability could be genetically fixed in the population.

The situation is different in environments where the power of abiotic processes significantly exceeds the community's productivity. In such environments plants that are protected against destabilised consumption by heterotrophs will not have any advantage over those that are not. Indeed, if the community's environment fluctuates due to powerful abiotic processes, the minimisation of biotic fluctuations is of no use, as it will not lead to a stable environment anyway.

Such a situation can be found in early successional communities that form in forest ecosystems after large-scale disturbances like, for example, fire, windfall or clear-cutting. During the first years after disturbance, the biotic productivity of the community is low, while the physical fluxes destroying the local environment are very powerful. Studying export of chemical elements in stream water from an experimentally clear-cut watershed during several years after clear-cutting, Bormann and Likens (1979) showed that the clear-cut forest was losing organic and inorganic (calcium, potassium, nitrate) nutrients at a rate several hundred times higher than the reference forested area of equal size. (On a local scale, a similar situation is to be found in treefall gaps.) Another type of environments where environmental fluctuations are beyond the control of the local biota are rapid water streams-rivers, sea streams, intertidal streams etc. Indeed, if the flux of matter in the stream is more powerful than local biotic productivity, the local environment will be shaped by the characteristics of the stream rather than by functioning of the local biota.

Our approach predicts that in such unstable communities the ecological restrictions on fluctuations of plant biomass due to consumption by heterotrophs are either significantly lessened or completely absent. This leads to disappearance of the dependence of the share of energy consumption over body size, which in stable ecosystems is dictated by Eq. (8). Hence, we can expect that in unstable ecosystems the energy partitioning among organisms of different body size should be more chaotic and, on average, more equitable. The logarithmic $\beta-M, D-M$ and $B-M$ distributions, Eqs. (12)-(14), should be on average flatter in unstable as compared to stable ecological communities.

\section{Testing the theory by empirical data}

\subsection{Stable ecological communities of boreal forests}

Despite the numerous data sets describing population density of the largest heterotrophs (mammals and birds) available in the literature (Nee et al., 1991; Brown and Maurer, 1986; Robinson and Redford, 1986; Damuth, 1993; Greenwood et al., 1996), we did not find studies where the degree of the environmental stability of the studied ecological communities was explicitly assessed. However, we were able to make a compendium of population density data of species inherent to stable ecological communities of boreal 
forests (see Table 1 and Appendix C). The primary (undisturbed, climax) boreal forest communities in Eurasia and North America are dominated by conifers (e.g., Picea, Larix, Abies spp.).

The basis for our compendium was formed by the data of Semionov-Tyan-Shansky (1982), who described the entire mammalian community of the Lapland State Nature Reserve, based on several decades of studies and with detailed accounts of feeding habits, population density and preferred habitats. Primary vegetation in the Lapland Nature Reserve is dominated by spruce Picea obovata. Semionov-Tyan-Shansky listed 39 mammalian species, among which 19 are plant-feeding. Among these, only ten species can be classified as belonging to the primary forest community (i.e., depend on it in terms of food supply and territory usage). The remaining nine species prefer biomes with different degrees of disturbance (clear-cuttings, riparian vegetation (e.g., beaver), flooded meadows, etc.) or non-forest ecosystems (tundra). Such species were excluded from the analysis.

The second source of data was a study of Grodzinski (1971) who assessed consumption of plant biomass by small mammals in Alaskan taiga forest dominated by Picea glauca. Geographic latitude of Grodzinski's study site is very close to that of Lapland State Nature Reserve. Additionally, the population density of Sciurus vulgaris and Eutamias sibiricus, two commonest rodent species of coniferous forests of the Eurasian boreal zone-both are strongly dependent on seed supply by conifers-were determined from different published sources, as well as the population density of roe deer Capreolus capreolus and musk deer Moschus moschiferus, an ungulate inhabiting mountainous forests of the boreal zone in Siberia (Table 1).

In an illuminating study Holling (1992) showed that the distribution of both mammalian and avian species number over body size is clustered. That is, there are 'preferred' values of body size $l_{1}, l_{2}, l_{3}$ (or $M_{1}$, $M_{2}, M_{3}$ etc.), at which the number of species peaks, while for the intermediate body sizes it drops significantly. Holling (1992) pointed out that the spacing of 'preferred' body size values along the body size axis is roughly proportional to body mass. We do observe this pattern for the typical representatives of the boreal forest community. There are species with body mass of about $M_{1} \sim 20-30 \mathrm{~g}, M_{2} \sim 200-300 \mathrm{~g}, M_{3} \sim$ $2-3 \mathrm{~kg}, M_{4} \sim 20 \mathrm{~kg}$ and the largest heterotrophs have
$M_{5} \sim 200-400 \mathrm{~kg}$. In Table 1 species are grouped in numbered size classes, from 1 to 5, while the attached capital letters refer to the particular ecosystem studied.

The list of the major plant-feeding heterotrophs of the boreal forest community would be incomplete without representatives of the Tetraonidae family of birds. In Eurasia these are hazel grouse Bonasa bonasia and wood grouse Tetrao urogallus. Spruce grouse Falcipennis canadensis enters size class 2 of the Alaskan spruce forest ecosystem. Needles of the dominant coniferous trees play a major role in the diets of both $F$. canadensis and T. urogallus. $B$. bonasia feeds on the phytomass of co-dominant deciduous trees (e.g., birch) and under-canopy vegetation (Potapov, 1990). As is clear from Table 1, these birds make considerable contributions into energy consumption of the corresponding size intervals, so that their omission would be unjustified. As for the other birds, their population densities are on average more than an order of magnitude lower than those of mammals of comparable body size (Rogacheva and Vakhrushev, 1983; Greenwood et al., 1996). Besides, the majority of species in the boreal zone are smaller than the body size intervals considered here $(\geq 20 \mathrm{~g})$ and most of them are insectivorous rather than plant-feeding, which was also the reason for omitting the smallest mammals from the present analysis. In boreal forest the smallest mammals are mostly represented by members of the Insectivora order (Semionov-Tyan-Shansky, 1982).

Summing up, the data of Table 1 include one complete census of large plant-feeding heterotrophs in a local ecological community (Lapland State Nature Reserve, spruce forest), as well as mean values for other ecological communities of the boreal zone.

Based on double-labelled water measurements, Nagy (1987) derived the following formula for the field metabolic rates of mammals $R_{\mathrm{M}}$ and birds $R_{\mathrm{B}}$ (see, however, Makarieva et al. (2003) for the break of metabolic rate scaling in the largest mammals):

$$
\begin{aligned}
& R_{\mathrm{M}}=0.069\left(\frac{M}{M_{0}}\right)^{0.727}\left(\mathrm{~W}_{\text {individual }^{-1}}\right), \\
& R_{\mathrm{B}}=0.126\left(\frac{M}{M_{0}}\right)^{0.640}\left(\mathrm{~W} \text { individual }^{-1}\right), \\
& M_{0}=1 \mathrm{~g}
\end{aligned}
$$


Table 1

Population density $D$ (individual $\mathrm{km}^{-2}$ ) of plant-feeding mammals and birds (b) inhabiting primary forests of the boreal zone

\begin{tabular}{|c|c|c|c|c|c|c|c|}
\hline \multirow[t]{2}{*}{ Size group } & \multirow{2}{*}{$\begin{array}{l}\text { Mean } \\
M\end{array}$} & \multicolumn{3}{|l|}{ Species } & \multirow[t]{2}{*}{ Total $D$} & \multirow[t]{2}{*}{ Comments } & \multirow[t]{2}{*}{ Source } \\
\hline & & Name & $M_{\mathrm{sp}}$ & $D_{\mathrm{sp}}$ & & & \\
\hline \multirow[t]{2}{*}{$1 \mathrm{~A}$} & \multirow[t]{2}{*}{25} & Clethrionomys rutilus & 22 & 2500 & \multirow[t]{2}{*}{3180} & Alaska, $64^{\circ} 50^{\prime} \mathrm{N}, 147^{\circ} 50^{\prime} \mathrm{W}$ & \multirow[t]{2}{*}{1} \\
\hline & & Microtus oeconomus & 28 & 680 & & $\begin{array}{l}\text { Spruce-dominated (Picea } \\
\text { glauca) forest; } \\
P_{1}=0.14 \mathrm{~W} \mathrm{~m}^{-2}\end{array}$ & \\
\hline \multirow[t]{7}{*}{$1 \mathrm{~L}$} & \multirow[t]{7}{*}{38} & Clethrionomys rufocanus & 38 & 2150 & \multirow[t]{7}{*}{3160} & $\begin{array}{l}\text { Lapland State Nature Reserve, } \\
\text { Russia, } 68^{\circ} \mathrm{N}, 32^{\circ} \mathrm{E}\end{array}$ & \multirow[t]{7}{*}{2} \\
\hline & & Clethrionomys glareolus & 27 & 760 & & Spruce-dominated (Picea & \\
\hline & & Myopus schisticolor & 30 & 170 & & obovata) forest; & \\
\hline & & Clethrionomys rutilus & 25 & 27 & & $P_{1}=0.14 \mathrm{~W} \mathrm{~m}^{-2}$ & \\
\hline & & Microtus oеconomus & 52 & 24 & & & \\
\hline & & Lemmus lemmus & 69 & 20 & & & \\
\hline & & Microtus agrestis & 52 & 6.8 & & & \\
\hline $2 \mathrm{~S}$ & 100 & Eutamias sibiricus & 100 & 300 & 300 & $\begin{array}{l}\text { Central Siberia, primary } \\
\text { forests dominated by cedar } \\
(\text { Pinus sibirica) and fir }(\text { Abies } \\
\text { sibirica }), 52-57^{\circ} \mathrm{N}, 92-103^{\circ} \mathrm{E} ; \\
P_{1}=0.37 \mathrm{~W} \mathrm{~m}^{-2} \text {, mean } D \\
\text { value over several population } \\
\text { cycles and types of major } \\
\text { habitats }\end{array}$ & 5 \\
\hline \multirow[t]{3}{*}{$2 \mathrm{~A}$} & \multirow[t]{3}{*}{290} & Tamiasciurus hudsonicus & 230 & 100 & \multirow[t]{3}{*}{130} & Mammals same as in $1 \mathrm{~A}$, bird & 1 \\
\hline & & Glaucomys sabrinus & 170 & 20 & & F. canadensis included as an & 3(b) \\
\hline & & Falcipennis canadensis (b) & 600 & 10 & & $\begin{array}{l}\text { inherent inhabitant of Alaskan } \\
\text { spruce forests }\end{array}$ & \\
\hline \multirow[t]{2}{*}{$2 \mathrm{~L}$} & \multirow[t]{2}{*}{300} & Sciurus vulgaris & 300 & 0.7 & \multirow[t]{2}{*}{11} & \multirow[t]{2}{*}{ Same as in 1} & \multirow[t]{2}{*}{2} \\
\hline & & Bonasa bonasia $(b)$ & 300 & 10 & & & \\
\hline \multirow[t]{2}{*}{ 2B } & \multirow[t]{2}{*}{300} & Sciurus vulgaris & 300 & 12 & \multirow[t]{2}{*}{22} & \multirow{2}{*}{$\begin{array}{l}\text { Means for the boreal zone of } \\
\text { Eurasia; } P_{1}=0.37 \mathrm{~W} \mathrm{~m}^{-2}\end{array}$} & 4 \\
\hline & & Bonasa bonasia $(b)$ & 300 & 10 & & & $3(b)$ \\
\hline \multirow[t]{2}{*}{$3 \mathrm{~L}$} & \multirow[t]{2}{*}{3300} & Lepus timidus & 3500 & 0.2 & \multirow[t]{2}{*}{2} & \multirow[t]{2}{*}{ Same as in $1 \mathrm{~L}$} & \multirow[t]{2}{*}{2,6} \\
\hline & & Tetrao urogallus $(b)$ & 3100 & 1.8 & & & \\
\hline $4 \mathrm{M}$ & $15 \times 10^{3}$ & Moschus moschiferus & $15 \times 10^{3}$ & 0.88 & 0.9 & $\begin{array}{l}\text { Mountain taiga of the Central } \\
\text { Siberia dominated by fir Abies } \\
\text { sibirica; } P_{1}=0.37 \mathrm{~W} \mathrm{~m}^{-2}\end{array}$ & 7 \\
\hline 4B & $20 \times 10^{3}$ & Capreolus capreolus & $22 \times 10^{3}$ & 1 & 1 & $\begin{array}{l}\text { Means for the boreal zone of } \\
\text { Eurasia; } P_{1}=0.37 \mathrm{~W} \mathrm{~m}^{-2}\end{array}$ & 8 \\
\hline \multirow[t]{2}{*}{$5 \mathrm{~L}$} & $244 \times 10^{3}$ & Alces alces & $400 \times 10^{3}$ & 0.1 & 0.12 & Same as in $1 \mathrm{~L}$ & 2 \\
\hline & & Ursus arctos & $150 \times 10^{3}$ & 0.016 & & & \\
\hline $5 B$ & $280 \times 10^{3}$ & Alces alces & $400 \times 10^{3}$ & 0.11 & 0.17 & Means for the boreal zone of & 8 \\
\hline & & Ursus arctos & $200 \times 10^{3}$ & 0.058 & & Eurasia; $P_{1}=0.37 \mathrm{~W} \mathrm{~m}^{-2}$ & \\
\hline
\end{tabular}

Note. $M_{\mathrm{sp}}$ is species body mass (mean of average male and average female adult mass) ( $\mathrm{g}$ ); mean body mass $M$ (g) is the geometric mean of $M_{\mathrm{sp}}$ values of all species from the same size group; $D_{\mathrm{sp}}$ is population density of a given species (individual $\mathrm{km}^{-2}$ ); total $D$ is the sum of $D_{\mathrm{sp}}$ values of all species from the same size group; $P_{1}$ is ecosystem net primary productivity. Sources: (1) Grodzinski, 1971; (2) Semionov-Tyan-Shansky, 1982; (3) Potapov, 1990; (4) Kozlov, 1990, Karpukhin et al., 1990; (5) Shtilmark, 1963, 1966; Shvedov, 1966; (6) Shubin, 1990, Lyalin, 1990, Berezin, 2003; (7) Kozhechkin, 1990; Mosheva, 2000; (8) Appendix C. The work of Mosheva (2000) on M. moschiferus contains a compilation of data over the entire area of the species distribution in Russia. Capital letters in the names of size groups denote: (A) Alaska, (L) Lapland State Nature Reserve, (B) boreal forests (mean), (S) Siberia, (M) mountain taiga. 


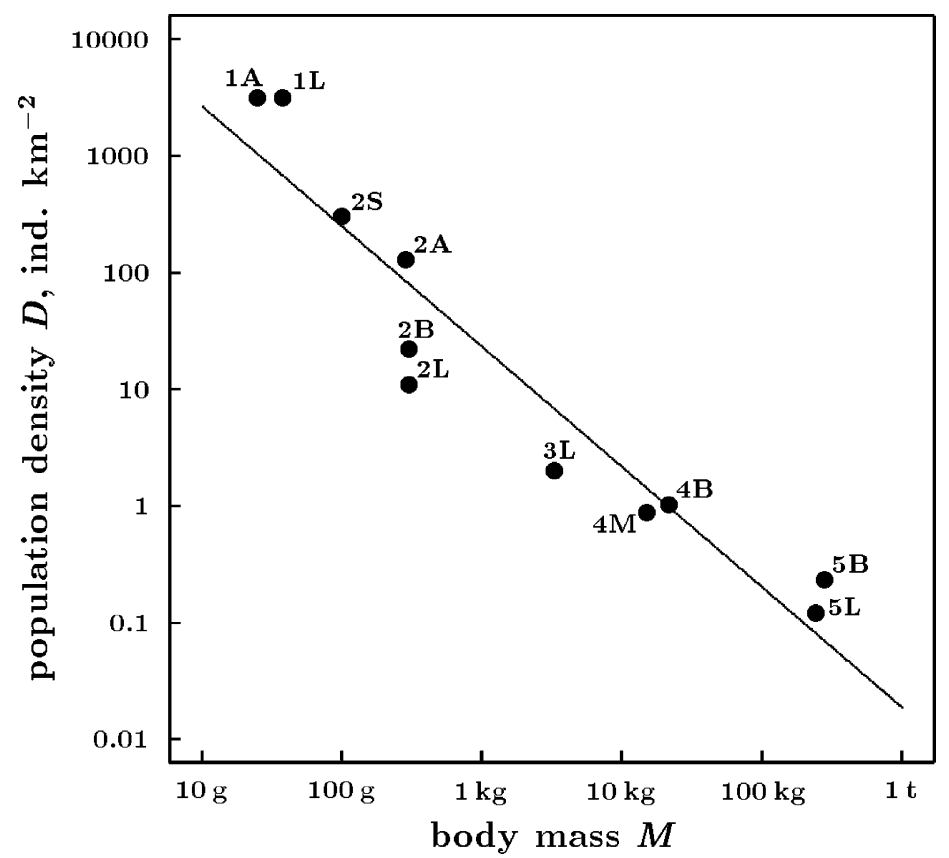

Fig. 2. Population density of plant-feeding animals vs. size-class body mass in boreal forest communities. Circles denote size groups from Table 1. See text for regression parameters.

As far as the majority of species analysed are mammals, Eq. (13) predicts that population density $D$ of animals from each size class should decline as $D \propto$ $1 /(l R) \propto M^{-1.06}$, where $M$ is the mean mass for size class and $l \propto M^{1 / 3}$.

Using the data of Table 1 we obtained the following parameters for the regression $\log D=a+b \log M(M$ is in grams, $D$ is in individual $\left.\mathrm{km}^{-2}\right): a=4.45 \pm$ 0.39 ( \pm S.D.), $b=-1.03 \pm 0.11, r^{2}=0.90$ (Fig. 2). This is in good agreement with the predicted value of -1.06 . If one takes the data for the local community of Lapland State Nature Reserve only (size groups 1L, 2L, 3L and 5L), one obtains remarkably close values, although with expectedly higher uncertainties: $a_{\mathrm{L}}=$ $4.41 \pm 1.05, b=-1.06 \pm 0.30, r^{2}=0.86$. (All linear regressions used in this study are OLS regressions).

According to Eq. (13), the absolute value of population density of heterotrophs of a given body size is proportional to ecosystem's net primary productivity $P_{1}$. Grodzinski (1971) estimate the net primary productivity of the studied ecosystem as $P_{1}=0.14 \mathrm{~W} \mathrm{~m}^{-2}$. This value is close to the lower boundary of $P_{1}$ values recorded in boreal forests: $0.1-1.0 \mathrm{~W} \mathrm{~m}^{-2}$ with a mean of $P_{1}=0.37 \mathrm{~W} \mathrm{~m}^{-2}$ (Lieth, 1975). We assumed
$P_{1}=0.14 \mathrm{~W}^{-2}$ for Alaskan and Lapland Nature Reserve study sites (size classes 1A, 2A, 1L, 2L, 3L, 5L) and $P_{1}=0.37 \mathrm{~W}^{-2}$ for the remaining ecosystems, Table 1. Linear regression of $\log \left(D / P_{1}\right)$ on $\log M$ produced a slope of $-1.12 \pm 0.12\left(r^{2}=0.91\right)$, which is again in good agreement with the theoretically predicted value of -1.06 . The agreement between the logarithmic $\left(D / P_{1}\right)-M$ and $D-M$ slopes $(-1.03 \pm 0.11$ versus $-1.12 \pm 0.12$ ) shows that the possible trend introduced by the net primary productivity $P_{1}$ into the analysed data set is not significant (i.e., that the analysed data contain no artificial correlation between $D$ and $P_{1}$ ).

\subsection{Mammalian population density data of Damuth} (1981, 1987, 1993)

Damuth (1987) collected data on population density of several hundred mammalian species and observed a logarithmic $D-M$ slope close to -0.75 . Our theoretically predicted slope of -1.06 is significantly steeper than Damuth's.

We argue that the major reason for such a discrepancy is that in Damuth's data set population densities 
of mammals from ecosystems with varying degrees of stability-from intact rainforests to agricultural complexes-were pooled together. Today most part of land is perturbed by anthropogenic activity (Whittaker and Likens, 1975), so only a few studies are expected to report population densities from stable natural ecosystems. As far as we predict that with growing instability and environmental disturbance the logarithmic $D-M$ slope should become shallower (Section 4 ), pooling all the data in one dataset is to produce $D-M$ slopes shallower than -1.06 .

Before confirming our argument by quantitative data, we dwell on the problem of ecologically relevant population density of species (Haila, 1988; Blackburn and Gaston, 1996). One usually discerns between 'crude' population density measured on a geographic scale and 'ecological' density which is calculated on the basis of habitats which the organism actually uses. However, there are no quantitative scientific criteria of defining the appropriate space scale of measuring population density.

We would suggest adding the environmental stability dimension to this problem. This can be best illustrated on a concrete example. A large herbivore of the boreal zone, moose Alces alces, feeds on bark, stems and foliage of shrubs and young trees. These food resources are concentrated on areas recovering from a recent disturbance like clear-cutting or fire, and, more locally and naturally, on treefall gaps. The population density of moose in such areas is higher than in the adjacent areas.

As discussed in Section 4, such habitats are environmentally unstable, suffering, for example, from rapid soil erosion. However, as forest succession continues, the process of environmental degradation initiated shortly after disturbance is first stopped and then reversed. At the ultimate stable stage of forest community's development the chemical composition of soil is restored to its initial undisturbed state. Hence, a forested area can be in environmental equilibrium if only the stabilising processes occurring on late successional sites are more powerful than the destabilising environmental processes on early successional sites. This condition sets a ceiling to the proportion of early successional sites a sustainable forest ecosystem can afford and, hence, to a sustainable population density of moose.
Imagine that we turn forest as a whole into an early successional habitat (e.g. by clear-cutting) and then artificially impede the successional process of recovery by introducing additional periodic disturbances-a similar situation is found on pastures and croplands. At first, the population density of moose radically increases. However, the inevitable environmental degradation of the intrinsically unstable early successional habitats will ultimately lead to the decline of moose population density and may even cause its complete extinction.

Thus, the ecological population density of moose observed in its preferred early successional habitats cannot be sustained if there are no adjacent late successional habitats. In natural undisturbed forests, the sustainable population density of moose is likely to be determined by the relative area the treefall gaps occupy in the forest. That is, by the dynamic equilibrium between fall and re-growth of trees. Once one treefall site recovers to a degree when the concentration of food resources of the moose substantially drops, the moose starts feeding on a newly formed treefall site.

Hence, a territory controlled by an individual animal should contain both late successional sites where it fed in the past and where the concentration of food resources is currently low, early successional sites where it feeds at present and where the concentration of food resources is maximum, and undisturbed sites with adult trees where the concentration of food resources is virtually zero, but which will become treefall sites in the future. Population density of species measured on such an environmentally sustainable territory is likely to be the most appropriate and meaningful variable for the studies of natural ecosystems. It is reasonable to call such population density sustainable.

Ideally, sustainable population density of large animals should be measured on an extensive territory of a geographic size (e.g., $100 \mathrm{~km} \times 100 \mathrm{~km}$ ) undisturbed by anthropogenic activity. Within this territory (which can represent an assemblage of different habitats like forests, bogs, rivers, etc.) one should map home ranges of the studied animals (i.e., territory actually visited by them) and calculate the sustainable population density dividing the total number of animals by the cumulative area occupied by their home ranges (this area will be generally less than the total area considered). Within the boreal zone, the most extensive territories occupied by primary undisturbed forests are found in 
Russia (Bryant et al., 1997). Population densities calculated on such territories (Table 1 and Appendix C), are likely to be the best available estimates of sustainable population density. Local ecological population density calculated in environmentally unstable habitats are therefore gross overestimates of sustainable population density.

To this end it is instructive to compare the intercepts of the linear $\log D-\log M$ regressions found in Damuth's (1987) extensive survey with that of Fig. 2. For primary consumers Damuth (1987) reports an intercept $a_{\mathrm{D}}=4.15$ when $D$ is measured in individual $\mathrm{km}^{-2}$ and mass $M$ in grams. This corresponds to a population density of $10^{4.15}=$ $1.4 \times 10^{4}$ individual $\mathrm{km}^{-2}$ for a $1 \mathrm{~g}$ mammal. The intercept characterising regression in Fig. 2 is $a=$ $4.45 \pm 0.39$, the uncertainty limits including Damuth's value. Hence, one can conclude that mean population densities of small mammals in our study and in Damuth's study approximately coincide.

The difference in slopes $(-1.03$ versus -0.73 for Damuth's primary consumers) is therefore due to lower population densities of large animals observed in our study. For example, Damuth's reports population density of Alces alces equal to 0.72 individual $\mathrm{km}^{-2}$. This is about seven times higher than our estimate 0.11 individual $\mathrm{km}^{-2}$ (Appendix C) obtained from averaging extensive surveys of moose populations in European and Siberian forests. An insight into ecological implications of such a high density can be gained from work of Adamovitch and Vatolin (1973), which is one of the fourteen literature sources used by Damuth (1987) for calculation of moose mean population density. Adamovitch and Vatolin (1973) studied habitat properties that can ensure maximum population density of moose under conditions of intensive forest exploitation. They found that a population density of 0.8 individual km$~^{-2}$ can be maintained in a forest if $60-80 \%$ of its area is represented by clear-cuts. Obviously, such a high population density by far exceeds the environmentally sustainable one. Additionally, Adamovitch and Vatolin (1973) drew the attention to overly high population density of animals that are observed in nature reserves if these represent 'islands' of protected natural areas surrounded by territories under intensive anthropogenic pressure, including hunting. Animals can maintain high population densities in such reserves even if food resources are insufficient, thus exhausting the vegetation of the protected area. As Adamovitch and Vatolin point out, animals "prefer hunger to being killed outside the reserve". Among the remaining 13 sources of moose data used by Damuth (1987), three describe populations in nature reserves in Central Europe (where natural forests are practically absent (Bryant et al., 1997)), one describes a moose population "on a burn" and another one pertains grassland biomes.

Another reason for high population density of animals in national parks and nature reserves is the creation by man of additional food resources (Jonkel, 1970; Bobyr, 1987). This can explain the more than twofold difference between mean population densities of bear Ursus arctos reported by Damuth (1987) (0.129 individual $\mathrm{km}^{-2}$ based on four data sources among which at least one describes a nature reserve) and our estimate of 0.058 individual $\mathrm{km}^{-2}$, based on studies of fourteen regions of brown bear habitats in Eurasia, Appendix 3. Population density of hare Lepus timidus (L. t. scotticus subspecies) reported by Damuth (1987), 18.6 individual $\mathrm{km}^{-2}$, was recorded on deforested hills of Scotland and exceeds the population density of L. timidus observed in European and Siberian forests by almost two orders of magnitude. Usual population density of L. timidus in Lapland State Nature Reserve is 0.2 individual $\mathrm{km}^{-2}$ (Semionov-Tyan-Shansky, 1982). Shubin (1990) reports exactly the same value for the Tomsk $\left(57^{\circ} \mathrm{N}\right.$, $85^{\circ} \mathrm{E}$ ) region of Siberia and characterises it as "sufficiently high". Similarly, for different types of hare habitats in the Omsk $\left(55^{\circ} \mathrm{N}, 73^{\circ} \mathrm{E}\right)$ region, Berezin (2003) reported population densities of L. timidus from 0.1 to 0.5 individual $\mathrm{km}^{-2}$.

A detailed analysis of each species with respect to environmental stability of the studied habitat will help to reveal to what extent the data of Damuth (1987) represent natural sustainable and disturbed unsustainable environments. Special attention should be paid to African mammals from the protected areas, where the situation can be similar to that found in the moose population - animals may concentrate in protected areas escaping from hunting and/or attracted by artificial food and water resources. For example, Cowling and Kerley (2002) studied the impact of elephants Loxodonta africana on the flora of the succulent thicket in the Addo Elephant National Park, Africa, which was created specifically to protect 
the dramatically threatened population of elephants. Cowling and Kerley (2002) point out that population density of $1.6-3.8$ individual $\mathrm{km}^{-2}$ is dramatically above "the carrying capacity" of the ecosystem and show that there is no ecological equilibrium in the succulent thicket exposed to such a high pressure. Damuth's (1987) value of 1.09 individual $\mathrm{km}^{-2}$ for L. africana is too close to these critical values to be considered as an estimate of sustainable population density in elephants.

In the absence of detailed data on the degree of environmental stability, in the zeroth approximation the ecosystems can be divided into closed (forests, woods) and open (savannahs, grasslands, agricultural landscapes etc.). Rates of soil erosion being highest in grasslands and lowest in the forests (Lal, 1990), closed ecosystems can be considered as more stable than open ones. Damuth (1993) lists 39 values of scaling exponent in the $D-M$ relationship for 557 species of mammals grouped according to dietary categories, geographic region and habitat type, closed (forest), open (savannah and grassland) and desert (only one value for this habitat type was given, we combine it with open habitats). The scaling exponents vary from -1.4 to +0.42 , with a mean value of -0.71 .

However, if one analyses the scaling exponents separately in closed and open ecosystems pooling all dietary groups together, one observes that, in agreement with our theory, the closed (more stable) ecosystems are characterised by a much lower scaling exponent than open (less stable) ones, $-0.88 \pm 0.31(n=22)$ versus $-0.50 \pm 0.40(n=17)$. Here $n$ is the number of scaling exponents averaged for each habitat type. For plant-feeding mammals (all dietary groups combined excluding carnivores, myrmecophages and insectivores-omnivores) the difference becomes even more pronounced: $-0.88 \pm 0.31(n=12)$ versus $-0.36 \pm 0.41(n=11)$. In both cases the difference is statistically significant at $P<0.01$.

More qualitatively, the same pattern is confirmed by Coley and Barone (1996) who analysed patterns of herbivory in tropical forests. They noted that the biomass of herbivorous mammals in tropical forests constitutes no more than $12-30 \%$ of mammalian biomass in savannahs (known as highly unstable ecosystems, both in terms of environmental parameters and plant biomass (Van de Koppel and Prins, 1998)). Odum (1971) noted that in forests only 5-10\% of the net primary productivity is consumed by the largest (aboveground) heterotrophs, the rest organic matter is decomposed in soil. While on grasslands and pastures, this share rises up to 40-60\%. Petrusevich and Grodzinsky (1973) studied absolute rates of consumption of live plant biomass in 29 ecosystems and noted the one to two orders of magnitude difference between ecosystems of grassland type and forest ecosystems (on average, $2500 \mathrm{kcal} \mathrm{ha}^{-1}$ per year in grasslands versus $100 \mathrm{kcal} \mathrm{ha}^{-1}$ per year in forests).

We conclude that the available data on population density of mammals are consistent with our theoretical prediction that in environmentally unstable ecosystems, where restrictions on biotic fluctuations of consumption of plant biomass are lessened, the distribution of energy consumption among herbivores of different body size becomes more equitable, with larger plant-feeding animals consuming equal or larger amounts of net primary productivity than smaller ones.

\subsection{Size spectra in aquatic ecosystems}

Despite fundamental differences in biological organisation, aquatic ecosystems appear to conform to the same rule: ecosystem stability is associated with lower energy flow through larger individuals.

Sprules and Munawar (1986) compared scaling exponents in the $D-M$ relationships for 67 plankton samples (fresh particle weight from $10^{-10}$ to $10^{-3} \mathrm{~g}, D$ is the number of individuals per unit volume in a logarithmic size class) from the Central Gyre in the North Pacific Ocean, inland Ontario lakes and Laurentian Great Lakes Superior, Huron, St.-Clair, Erie and Ontario. The observed scatter of $D-M$ scaling exponents ranged from $b=-0.76$ (central stations in Lake Erie) to $b=-1.16$ (open ocean). It was pointed out that the most stable ecosystems like those of the open ocean, $b=-1.16$, and large oligotrophic lakes like Lake Superior, $b=-1.10$, are not only characterised by the lowest values of the scaling exponent, but also by the highest correlation coefficients describing the $D-M$ spectra $\left(r^{2}=0.97\right.$ and $0.94-0.98$, respectively). Unstable and destabilised aquatic ecosystems, like shallow lakes receiving major nutrient discharges from the inflowing rivers (Lake St.-Clair) or lakes with a high degree of contamination (Lakes Ontario and Erie), demonstrate the shallowest logarithmic $D-M$ slopes $b$ and the lowest correlation coefficients. 
A similar difference between energy partitioning patterns in stable versus unstable ecosystems can be traced within separate trophic groups. Biddanda et al. (2001) measured bacterial respiration in Lake Superior and several small Minnesota lakes, differing greatly in the degree of eutrophy (chlorophyll content from 0.57 to $53 \mu \mathrm{g} \mathrm{l}^{-1}$ ). In the most stable ecosystem of Lake Superior and other oligotrophic lakes bacterial respiration accounts for more than $90 \%$ (from 91 to $98 \%$ ) of the total planktonic respiration. That is, the smallest heterotrophs fully control the fluxes of organic matter decomposition in stable aquatic ecosystems. This was also confirmed by studies of the open ocean (Del Giorgio et al., 1997). With increasing eutrophy, the share of bacterial respiration decreases down to $9 \%$ (Lakes Medicine and Mitchell), indicating the growing role of larger heterotrophs in such ecosystems.

We note in passing that the fact that environmental instability of eutrophic aquatic systems is as a rule coupled with high biological productivity finds a purely ecological explanation within our approach, i.e., if one assumes that ecological communities are organised in a way maximising their stability. Where external matter fluxes shaping the community's environment are low, like in stable oligotrophic systems, a low biotic productivity is enough to keep the environment under control. Where such fluxes are high (e.g., nutrient discharges from the coastal zone), the more productive the ecological community, the more control it can impose on the environment. Hence, in highly fluctuating environments there appears a natural selection gradient towards higher biological productivity.

The lowest trophic level-phytoplankton-shows the same response to the degree of environmental stability. In stable self-sustainable ecosystems relying of nutrient recycling the abundance of the smallest cells is higher than in ecosystems relying more on external nutrient input (see, e.g., Rodríguez et al., 2001 and references therein). In an extensive survey of phytoplankton size structure (6339 seawater samples) Li (2002) grouped the phytoplankton community into three size classes, the smallest $(<2 \mu \mathrm{m})$, intermediate $(2-10 \mu \mathrm{m})$ and largest $(10-20 \mu \mathrm{m})$ cells. The resulting more than tenfold range of linear size corresponds to at least three orders of magnitude change in cell mass.

Li (2002, Fig. 2a) showed that with chlorophyll concentration (a common measure of eutrophy) increasing from approximately 20 to $10^{3} \mathrm{mg} \mathrm{m}^{-2}$, the abundance (cells $\mathrm{m}^{-2}$ ) of the smallest phytoplankton decreased from $10^{13}$ to $10^{11}$ cells $\mathrm{m}^{-2}$, the abundance of the largest cells increased from $\sim 3 \times 10^{-9}$ to $10^{10}$ cells $\mathrm{m}^{-2}$, while the intermediate cells remained at a level of $\sim 10^{11}$ cells $\mathrm{m}^{-2}$. We conclude from these data that in stable ecosystems with low chlorophyll content a three orders of magnitude increase in cell mass corresponds to at least four orders of magnitude drop of abundance (from $10^{13}$ cells $\mathrm{m}^{-2}$ in the smallest to $10^{9}$ cells $\mathrm{m}^{-2}$ in the largest size class). This allows to roughly estimate the steepest logarithmic $D-M$ slope to be $(-4) / 3=-1.3$.

In the most eutrophic systems the corresponding decrease in abundance constitutes only one order of magnitude (from $10^{11}$ cells $\mathrm{m}^{-2}$ in the smallest and intermediate size class to $10^{10}$ cells $\mathrm{m}^{-2}$ in the largest size class). This would produces a slope of about $(-1) / 3$ $\sim-0.33$. A somewhat narrower range of slopes from -1.2 to -0.75 was observed in another extensive survey of phytoplankton size spectra (Rodríguez et al., 2001). (Note that Rodríguez et al. (2001) suggested that flatter slopes can be observed in areas with upward water flow retaining larger cells closer to the surface. However, only a limited range of vertical velocity values (from -5 (downward) to +5 (upward) $m$ per day against the observed range from -90 to $+40 \mathrm{~m}$ per day) was found to correlate with phytoplankton size spectrum slopes and the possible correlation of vertical velocity with environmental stability was not assessed).

Revealing direct coupling of the phytoplankton community structure with environmental stability, Li (2002, Fig. 3a) further shows that in highly stable waters, where the disturbing power of physical mixing fluxes is low, the smallest cells outnumber the largest ones by four to five orders of magnitude. Such environments are characterised by high non-random stratification and complete dominance of biotic processes over abiotic ones in maintenance of the community structure. With increasing degree of water mixing, the abundance of larger cells increases, while the phytoplankton size spectrum as a whole becomes more chaotic (Li, 2002). These results fully support our prediction that in stable ecological communities there are strong restrictions on fluctuations of fluxes of biological synthesis and decomposition that can be introduced by the larger organisms. These restrictions lead to suppression of energy flow through larger organisms. 
Neglecting the difference in environmental stability of the ecosystems studied and pooling all phytoplankton data in one plot, Li (2002, Fig. 2b) obtains a logarithmic $D-M$ slope of -0.78 , which is further interpreted as an extension of the energy equivalence rule for phytoplankton beyond laboratory cultures (Agustí and Kalff, 1989) and marine species in a coastal fjord of Sweden (Belgrano et al., 2002). (Note that the first example (laboratory cultures) is clearly not a natural system, while communities from coastal zones with their nutrient discharges from rivers and anthropogenic contamination are likely to represent unstable environments).

Similarly to the case of Damuth's data set, the meaningfulness of a logarithmic $D-M$ slope describing a random pool of stable and unstable ecosystems can be questioned. Depending on the degree to which stable and unstable ecosystems are represented in the samples studied, the resulting slope can vary nearly arbitrarily, depending on the researcher's preferences. Turning to objective criteria, one may note that as far as most part of the planet's surface is covered by open ocean with its stable oligotrophic ecosystems (Kirchman, 1997), the most negative slopes of the plankton $D-M$ relationship spectra are likely to have a much higher weight in describing natural macroecological regularities than the more shallower and chaotic planktonic spectra observed in the restricted unstable regions of the ocean. We also note that the consistency of trends in energy partitioning change between stable and unstable environments observed both in overall planktonic spectra (Sprules and Munawar, 1986), as well as within separate trophic groups like bacteria (Biddanda et al., 2001) or phytoplankton ( $\mathrm{Li}, 2002)$, refutes the attempts to ascribe the low slopes observed in aquatic size spectra solely to decreasing energy availability with increasing body size and growing trophic level of the studied organisms, assuming energetic equivalence within each trophic layer (see, e.g., Brown and Gillooly, 2003).

The limited data available for the higher trophic groups conform to the general pattern of shallow (significantly less than unity) slopes in unstable, fluctuating environments. Marquet et al. (1990) observed a logarithmic $D-M$ slope of -0.75 for macroinvertebrate species in the intertidal community of temperate coast in Chile, while in Panama an intertidal community showed no significant relationship between body size and population density (Navarrete and Menge, 1997). The upper boundary slope (log-log regression of highest species population densities within each size class over body size) was estimated by them to range from -0.128 to -0.344 . Knouft (2002) found an average logarithmic $D-M$ slope of -0.6 for fish species in 23 low- to mid-latitude streams. As already noted, both intertidal communities and streams represent environments shaped by powerful physical fluxes of matter rather than by the local biota.

In this section we pointed out consistent differences in logarithmic $D-M$ slopes observed in aquatic ecosystems with different degrees of environmental stability. We could not apply the predictions of our approach more quantitatively here due to less transparent spatial structure of aquatic ecosystems as compared to terrestrial ones. In particular, a fundamental issue is the value of spatial scale $s_{1}$ (ecosystem unit) for aquatic ecosystems. This is the scale within which the functioning of organisms is to a large degree correlated and at which they benefit from environmental stabilisation. In aquatic ecosystems there is a variety of organisation scales (from phytoplankton colonies $(0.1 \mathrm{~mm})$ to phytoplankton blooms $(100 \mathrm{~km})$ ), and further research is needed to find the ecologically relevant one. The increasing non-randomness of community structure in stratified waters allows to suggest that the spatial core of community structure is likely to be organised by heterotrophic organisms that normally reside at depth, where water mixing is practically absent or strongly suppressed. The well-known but yet largely enigmatic vertical migration of zooplankton (Lampert, 1989) may thus have a profound ecological meaning of an organising influence imposed by the well-structured zooplankton community on phytoplankton population continuously disorganised by intensive water mixing near the surface (Gorshkov et al., 2000, p. 138).

\subsection{Arthropods: data of Morse et al. (1988) for tropical rainforest}

Eqs. (12)-(14) were obtained for relatively large plant-feeding organisms, with linear size $l$ significantly exceeding the characteristic thickness $L$ of the consumed layer of plant biomass, $l \gg L$. The amount $f$ of plant biomass exempted by the animal in a single act of food intact was therefore proportional to the second power of the linear body size, Eq. (1). For 
the smaller plant-feeding organisms like insects $l \leq L$ and the amount of foot consumed per bite should be proportional to the volume (rather than area) of the food-gathering organ and can be written as

$f=\rho \delta l^{3}$,

where $\delta$ is a dimensionless coefficient describing the relative volume of the food-gathering organ and $\rho$ is the density of plant biomass. Small heterotrophs like insects operate with three-dimensional food concentrates, while ungulates and other large mammals have to deal with two-dimensional layers of uniformly distributed plant biomass.

Putting the newly defined $f$ (Eq. (16)) into all the formula of Section 2 instead of $f$ (Eq. (1)), we derive the following analogues of Eqs. (12)-(14) for the smaller heterotrophs:

$$
\begin{aligned}
\beta(l) & =\left(1-\frac{1}{k}\right) \frac{1}{l^{2}} \frac{\varepsilon_{1}^{2} s_{1}}{l_{\max } \delta \rho}, \\
D(l) & =\frac{\beta}{R} P_{1} \propto \frac{1}{l^{2} R}, \quad B(l)=D M \propto \frac{M}{l^{2} R} .
\end{aligned}
$$

With growing body size the amount of plant biomass consumed "per bite" by the small heterotrophs increases more rapidly $\left(\propto l^{3}\right)$ than in the larger animals $\left(\propto l^{2}\right)$, cf. Eqs. (1) and (16). Hence, to suppress the related increase of plant biomass fluctuations introduced by small heterotrophs, their share of energy consumption should drop more rapidly.

For insects the scaling exponent $\alpha$ in the $R-M$ dependence is of the order of $0.8-0.9$, with an average slope of $0.84 \pm 0.12$ reported for 44 insect species (Muthukrishnan and Pandian, 1987), similar to what was found by Lighton et al. (2001) for a larger sample of arthropod species. Assuming $R \propto M^{0.84}$ and recalling that we defined $l$ as $M^{2 / 3}$ we conclude from Eq. (17) that population density $D(l)$ within each logarithmic interval of body size of small heterotrophs should be proportional to $M^{-(\alpha+2 / 3)}=M^{-1.5}$.

Morse et al. (1988) reported size spectra of arboreal beetles ( 859 species) inhabiting tropical forests of Borneo. They showed that the population density of herbivorous beetles drops with increasing apparent body size $l_{\mathrm{a}}$ as $D(l) \propto l_{\mathrm{a}}^{-4.63 \pm 0.213}$. As long as the apparent linear size in arthropods is related to body mass as $M \propto l_{\mathrm{a}}^{2.62}$ (Stork and Blackburn, 1993), the observed dependence corresponds to $D(l) \propto M^{-4.63 / 2.62}=$
$M^{-1.77}$, which is satisfactorily close to the predicted value of -1.5 and much more negative than the slope of -1.03 observed in larger animals, see Section 5.1 (Fig. 4).

Morse et al. (1988) point out that in other insect communities the logarithmic $D-M$ slopes are much more shallow (Hijii, 1984; Kikuzawa and Shidei, 1967; Terakawa and Ohsawa, 1981; Lawton, 1986; Morse et al., 1985). Three of the five sources they cite describe presumably unstable or unnatural ecosystems: a plantation (Hijii, 1984), an experimental forest (Terakawa and Ohsawa, 1981) and a forest near industrial settlement (Kikuzawa and Shidei, 1967), so that shallow slopes observed there are in agreement with our theory. Siemann et al. (1999) studied the insect community in savannahs and grasslands. Their data (Siemann et al., 1999, Fig. 1a and 5 b) show that over a 3.5 orders of magnitude increase in body volume (starting from approximately $5 \mathrm{~mm}^{3}$ ), the population density of insects drops by about 2.5 orders of magnitude, which corresponds to a scaling exponent in $D-M$ relationship of about $(-2.5) / 3.5 \sim-0.7$, an expectedly shallow slope compared to the value of -1.5 predicted for stable ecosystems.

Morse et al. (1985) report similarly shallow slopes for eight arthropod communities, among which one pertains a successional stage of the forest community (birch forest), two describe cacao plantations, the vegetation in another two is characterised by the authors as "secondary" and one community was observed on riparian vegetation. All these environments can be justifiably classified as unstable. (Riparian vegetation is under continuous river impact). We conclude that the observed shallow slopes do not contradict our predictions, Eq. (17), valid for stable communities.

\subsection{Residents versus travellers: soil microorganisms and arthropod data of Stork and Blackburn (1993)}

Nevertheless, there exist extensive descriptions of arthropod communities that cannot be characterised as inhabiting unstable ecosystems. Stork and Blackburn (1993) show that the biomass of arthropods inhabiting tropical forests of Indonesia grows with body size, instead of decreasing as $B \propto M^{-0.5}$ as suggested by Eq. (17) and $R \propto M^{0.84}$ (Lighton et al., 2001). 
Within our approach, we can explain these data by assuming that a large proportion of the studied animals is represented by residents, i.e., organisms spending a significant part of their lifespan within borders of a single ecosystem unit (e.g. on a particular tree canopy). As discussed in Section 2, see text below Eq. (4), such organisms do not introduce any considerable fluctuations in the cumulative flux of decomposition within their home ecosystem unit. In simple words, if such an organism eats more on one leaf of the tree, it will eat less on another, so that the cumulative consumption will be as stable as are its metabolic requirements.

In contrast, if a highly mobile organism (traveller) eats too much on a leaf of one tree, with a high probability it will eat too little on a leaf of another, thus introducing fluctuations in the consumption process in both. As far as such fluctuations grow with increasing body size, the relative share of energy consumption $\beta$ of larger animals should be restricted. For residents, there can be no dependence of $\beta$ on $l$ (as far as for them $\sigma_{n}^{2}=0$, Eq. (4)), so that the energy equivalence rule can be applicable.
To quantitatively justify the proposed division of mobile organisms into residents and travellers we need to consider the characteristic movement velocities $u$. Moving at a speed $u$, the organism of linear body size $l$ scans an area of $u l$ per unit time. If the area scanned by the organisms during time $\tau_{1}$ (time of regeneration (turnover) of plant biomass) does not exceed a characteristic surface area in the ecosystem unit, such an organism can be a resident. If this area is much greater than $s_{1}$, we are likely to deal with a traveller.

In Table 2 we collected data on movement velocities $u$ of organisms with linear body size varying over six orders of magnitude. We can see that, on average, the movement velocity grows with body size. Unicellular organisms $\left(l \sim 10^{-5} \mathrm{~m}\right)$ move at speeds of about $u \sim$ $10^{-4} \mathrm{~m} \mathrm{~s}^{-1}$. In $\tau_{1} \sim 1$ year $=3 \times 10^{7} \mathrm{~s}$ they will scan an area of $u l \tau_{1} \sim 3 \times 10^{-2} \mathrm{~m}^{2}$, which is two to three orders of magnitude lower than the projection area of a tree canopy $s_{1}$. Obviously, unicells are residents.

The next group of organisms are crawlers (insect larvae, worms), walkers and runners with body sizes of $l \sim 10^{-3}-10^{-2} \mathrm{~m}$ and movement velocities of

Table 2

Characteristic movement velocity $u\left(\mathrm{~m} \mathrm{~s}^{-1}\right)$ of organisms with different linear body sizes $l(\mathrm{~m})$

\begin{tabular}{|c|c|c|c|c|}
\hline Organism & $l$ & $u$ & Way of movement & Source \\
\hline Bacterium Escherichia coli & $2 \times 10^{-6}$ & $3 \times 10^{-5}$ & Rotation of filaments & 1 \\
\hline Algae Chlamidomonas nivalis & $10^{-5}$ & $6 \times 10^{-5}$ & Swimming with use of filaments & 2 \\
\hline Dinoflagellate Peridinium gatunense & $3 \times 10^{-5}$ & $10^{-4}$ & Swimming & 2 \\
\hline $\begin{array}{l}\text { Insect larvae (blowfly, Diptera) } \\
\text { Protophormia terraenovae }\end{array}$ & $3 \times 10^{-2}$ & $10^{-3}$ & Crawling & 3 \\
\hline Earthworm Lumbricus terrestris & $\begin{array}{l}2 \times 10^{-3} \\
2 \times 10^{-2}\end{array}$ & $\begin{array}{l}10^{-3} \\
0.2 \times 10^{-3} \\
10^{-2} \\
0.2 \times 10^{-2}\end{array}$ & $\begin{array}{l}\text { Surface crawling } \\
\text { Burrowing } \\
\text { Surface crawling } \\
\text { Burrowing }\end{array}$ & 4 \\
\hline Spider Metepeira incrassata & $7 \times 10^{-3}$ & $10^{-3}$ & Walking & 5 \\
\hline Ant Pogonomyrmex rugosus & $2 \times 10^{-3}$ & $3 \times 10^{-2}$ & Running & 6 \\
\hline Beetle Phoracantha semipunctata & $10^{-2}$ & 0.15 & Running & 7 \\
\hline Bark beetles & $10^{-2}$ & 2 & Flight & 8 \\
\hline Fly Drosophila sp. & $10^{-3}$ & 1 & Flight & 9 \\
\hline Moth Agrius convolvuli & $2 \times 10^{-2}$ & 3 & Tethered flight & 10 \\
\hline Dragonfly Anax junius & $10^{-2}$ & 4 & Natural flight (feeding and migration) & 11 \\
\hline Bee Apis sp. & $5 \times 10^{-3}$ & $5-8$ & Flight & 9 \\
\hline Birds (several small species) & $\sim 0.05$ & $\sim 10$ & Flight & 12 \\
\hline \multirow[t]{2}{*}{ Mammals } & $0.04-0.70$ & $0.1-15$ & $\begin{array}{l}\text { Maximum running speeds supported } \\
\text { by aerobic metabolism }\end{array}$ & 13 \\
\hline & $0.02-0.70$ & 0.3 & Available daily speed & 14 \\
\hline
\end{tabular}

Note. As everywhere in the paper, linear body size is defined as $l \equiv(M / \rho)^{1 / 3}, \rho=1 \mathrm{~g} \mathrm{~cm}^{-3}, M$ is body mass. Sources: (1) Berg, 1996; (2) Hill and Häeder, 1997; (3) Berrigan and Lighton, 1993; (4) Quillin, 1999, 2000; (5) Jakob et al., 2001; (6) Lighton et al., 1993; (7) Hanks et al., 1996; (8) Byers, 1996; (9) Tucker, 1970; (10) Komai, 1998; (11) May, 1995; (12) Greenewalt, 1975; (13) Alexander and Maloiy, 1989; (14) Gorshkov et al., 2000, p. 87. 
about $10^{-3}-10^{-2} \mathrm{~m} \mathrm{~s}^{-1}$. As follows from Table 2, a spider annually scans about $210 \mathrm{~m}^{2}$ and a worker ant scans about $1800 \mathrm{~m}^{2}$. In tropical forests ants are common inhabitants of tree canopies (Blackburn and Gaston, 1993; Coley and Barone, 1996). If one assumes the canopy diameter to be about $d$ $\sim 15 \mathrm{~m}^{2}$ and leaf area index to be 10 (Whittaker and Marks, 1975), we obtain foliage surface area of a single tree to be of the order of $10 d^{2} \sim 2000 \mathrm{~m}^{2}$. This value approximately coincides with the area scanned annually by an ant and greatly exceeds the estimated areas scanned by fly larvae and spider. Note also that the real value of areas scanned are likely to be smaller than $u l \tau_{1}$, as far as arthropods are only active during some parts of the day (Basset et al., 2001). We thus conclude that arthropod runners, crawlers and walkers with linear body size not exceeding several millimetres can yet be residents.

It is further clear from Table 2 that all flying organisms (including beetles) should be classified as travellers. For a given body size, the velocity of flight exceeds the velocity of all types of non-flying movement by one to two orders of magnitude. The area scanned by flying insects exceeds by orders of magnitude any relevant surface areas within ecosystem units. Thus, all plant-feeding travellers-flying insects, birds and mammals-should conform to Eqs. (12)-(14) or (17). This explains why Morse et al. (1988) observed a drop of the share of energy consumption of the boreal beetles with increasing body size. That high mobility may be a reason for the observed size spectra in beetles was also mentioned by the authors themselves (Morse et al., 1988).

Stork and Blackburn (1993) present biomass size spectra for four ecological groupings of arthropodsherbivores, decomposers, carnivores and tourists. The latter grouping comprises organisms that do not have direct association with any particular part of the ecosystem unit (e.g., canopy, trunk, soil, etc.), but are occasionally found near trees during migration, dispersal, mating, etc. (Moran and Southwood, 1982; Evans and Jukes, 2000). Although characteristic movement velocities of tourists are not reported, it is clear that this grouping is likely to contain a more significant proportion of travellers than the three others. It is therefore remarkable that, as the authors point out, this grouping shows a different biomass spectrum than the three others. The biomass of herbivores, decomposers and carnivores grows with increasing body size over entire range of body size change (from less than 0.5 to $60 \mathrm{~mm}$ ) (Blackburn and Gaston, 1993). In tourists, the biomass grows sharply at very small body sizes (indicating, in agreement with Table 2, that there are very few travellers among the smallest arthropods) and then remains nearly constant with the apparent linear body size $l_{\mathrm{a}}$ changing from approximately $10^{-3}$ to $10^{-2} \mathrm{~m}$.

For residents a more equitable distribution of energy consumption rates over body size is possible and also confirmed by the available studies of soil microorganisms. For spherical microorganisms with body volume from 0.1 to $10^{3} \mu \mathrm{m}^{3}$ the biomass per gram soil increases consistently with body volume by one to two orders of magnitude depending on soil type (Lin and Brookes, 1999).

In this respect soil microorganisms appear to differ from aquatic ones for which in stable ecosystems the biomass can slightly decrease with body size, Section 5.3. A possible reason for that is the difference in spatial organisation of terrestrial and aquatic ecosystems. Primary producers in aquatic ecosystems reside in the upper part of water column penetrable by solar radiation. Decomposition of organic matter is biochemically light-independent, so that heterotrophs can reside at larger depths. Spatial distancing of synthesis and decomposition of organic matter in the aquatic medium leads to formation of vertical gradients of nutrient concentrations, which bring about downward fluxes of organic nutrients and upward fluxes of inorganic nutrients. Random vertical displacements of both primary producers and decomposers may affect the gradients and fluxes of nutrients, which leads to destabilisation of primary productivity in stable ecosystems relying heavily on nutrient recycling. Hence, aquatic ecosystems are likely to be more critically dependent on (vertical) mobility of organisms, including the smallest ones, as compared to terrestrial ecosystems where major fluctuations of consumption are due to horizontal movements of large heterotrophs (Fig. 1).

We conclude that in terrestrial ecosystems the energy flux can be distributed relatively equitably over different size-classes of organisms-residents due to the fact that such organisms introduce smaller fluctuations into the consumption flux as compared to travellers. 


\section{Share of energy consumption: absolute values}

\subsection{Estimating size-independent parameters of Eq. (12)}

So far we have mostly discussed the scaling exponents in body size relationships of $\beta, D$ and $B$. Such an emphasis is common to the majority of allometric studies (see those cited in Section 1). The widely discussed energy equivalence rule says that populations of differently sized species claim equal energy fluxes. But what are the absolute values of these fluxes and how these relate to ecosystem's primary productivity? To our knowledge, no theoretical studies were devoted to this problem although the problem itself has been well recognised (see, e.g., Lawton, 1990).

Our theoretical approach allows to predict the absolute fluxes of energy claimed by differently sized organisms, provided that parameters $\varepsilon_{1}, s_{1}, \delta$ and $l_{\max }$ entering Eqs. (12)-(14) are independently estimated.

Parameter $\varepsilon_{1}$ has the meaning of relative accuracy with which the primary producers of the ecosystem unit are able to stabilise the flux of photosynthesis and the amount of metabolically active plant biomass over a time period of plant biomass turnover $\tau_{1}$, Appendix A. In stable primary forest ecosystems, the dominant plants (trees) are responsible for the dominant part of ecosystem primary productivity and phytomass (Whittaker and Marks, 1975). The value of $\varepsilon_{1}$ can be therefore estimated as $\varepsilon_{1}^{2} \sim 1 / N_{1}$ (see Section 2 and Appendix A), where $N_{1}$ is the number of weakly correlated photosynthesising parts of the plant, in primary coniferous forests-needles. If needle biomass (per unit area) is $B_{\mathrm{n}}$, mean mass of one needle is $m$ and tree crown projection area is $s_{1}$, then we have $N_{1}=B_{\mathrm{n}} s_{1} / m$. The product $\varepsilon_{1}^{2} s_{1}$ in the nominator of the right-hand side in Eq. (12) can be therefore estimated as $\varepsilon_{1}^{2} s_{1}=m / B_{\mathrm{n}}$, dimension $\mathrm{m}^{2}$. We now estimate characteristic $\varepsilon_{1}^{2} s_{1}$ values for several dominant coniferous species of temperate forests.

For the fir tree Larix gmelinii we have $B_{\mathrm{n}}=100 \mathrm{~g}$ dry weight $\mathrm{m}^{-2}$ (Kajimoto et al., 1999). Assuming that the volume of one needle is about $1 \mathrm{~mm}^{3}$ (Vygodskaya et al., 1997) and taking 50\% water content (Larcher, 1980), we obtain $m \sim 5 \times 10^{-4} \mathrm{~g}$ dry weight and $\varepsilon_{1}^{2} s_{1} \sim 5 \times 10^{-6} \mathrm{~m}^{2}$. Bobkova and Galenko (2001) report that the total dry mass of all needles of an indi- vidual spruce tree Picea obovata $(20 \mathrm{~m}$ height, $20 \mathrm{~cm}$ diameter at breast height) amounts to $15 \mathrm{~kg}$ per tree. Taking the average crown projection area of similarly sized spruces not exceeding $s_{1} \sim 10 \mathrm{~m}^{2}$ (Karpov, 1983; Bragg, 2001), we obtain for P. obovata $B_{\mathrm{n}} \sim$ $1.5 \mathrm{~kg}$ dry weight $\mathrm{m}^{-2}$. Dry weight of one needle in Picea spp. is about $m \sim 3 \times 10^{-3} \mathrm{~g}$ (Karpov, 1983; Salih and Andersson, 1999). This gives for $P$. obovata $\varepsilon_{1}^{2} s_{1} \sim 2 \times 10^{-6} \mathrm{~m}^{2}$. Old-growth Douglas fir Pseudotsuga menziesii is characterised by mean total dry mass of needles of about $114 \mathrm{~kg}$ per tree (Ishii et al., 2002), mean crown projection area $s_{1}$ of about $82 \mathrm{~m}^{2}$ (so that $\left.B_{\mathrm{n}}=\left(114 \times 10^{3} \mathrm{~g}\right) /\left(82 \mathrm{~m}^{2}\right) \sim 1.4 \times 10^{-3} \mathrm{~g} \mathrm{~m}^{-2}\right)$ and mean dry mass of one needle $m \sim 4.5 \times 10^{-3} \mathrm{~g}$ (H. Ishii, personal communication). We thus have for $P$. menzieni $\varepsilon_{1}^{2} s_{1} \sim 3 \times 10^{-6} \mathrm{~m}^{2}$. For spruce Picea abies we have $B_{\mathrm{n}} \sim 300 \mathrm{~g}$ dry weight $\mathrm{m}^{-2}$ (Laitat et al., 2000) and $m \sim 3 \times 10^{-3}$ g dry weight (Karpov, 1983; Salih and Andersson, 1999), which yields $\varepsilon_{1}^{2} s_{1} \sim$ $10 \times 10^{-6} \mathrm{~m}^{2}$. Averaging the estimates obtained for the four conifers (Larix, Pseudotsuga, Picea obovata and $P$. abies) we assume $\varepsilon_{1}^{2} s_{1}$ to be about $5 \times 10^{-6} \mathrm{~m}^{2}$.

The largest plant-feeding animal of the boreal zone is the moose, Alces alces, with body mass of about $400 \mathrm{~kg}$ and linear body size $l_{\max } \sim 0.74 \mathrm{~m}$.

The remaining parameter to be estimated is $\delta$. This dimensionless parameter describes the area $s_{\delta} \equiv \delta l^{2}$ of animal's interaction with plant biomass as related to body surface area $l^{2}$. For ungulates $s_{\delta}$ can be the area of a single bite, for forager like man or primates this can be the area of a single grasp, for herbivorous birds $s_{\delta}$ can be estimated as gape area, etc. The fundamental nature of $s_{\delta}$ has been widely recognised in ecological studies (Hanley, 1982; Gross et al., 1993; Jiang and Hudson, 1994; Shipley et al., 1994; Bailey et al., 1996; Cohen et al., 1999; Ungar and Ravid, 1999). In Table 3 we present the available order-of-magnitude estimates of $\delta$ for several plant-feeding animals of different body sizes. On the basis of these data, we estimate the mean value of $\delta$ as $2 \times 10^{-2}$.

\subsection{Testing the numeric validity of Eq. (1)}

We are now in a position to test the numeric validity of Eq. (1) for description of a single act of food intake. Taking natural logarithms of both sides of Eq. (1) and recalling that $l \equiv(M / \rho)^{1 / 3}$, we obtain the following 
Table 3

Estimates of parameter $\delta$ for organisms with different body sizes and different food-gathering organs

\begin{tabular}{|c|c|c|c|c|c|}
\hline Organism & $M(\mathrm{~kg})$ & $s_{\delta}\left(\mathrm{cm}^{2}\right)$ & Comments on $s_{\delta}$ estimate & $\delta \times 10^{-2}$ & Source \\
\hline Bird Sylvia spp. & 0.02 & 0.49 & Squared gape width & 6 & 1 \\
\hline Mouse deer Tragulus javanicus & 1.4 & 1 & Bite area estimated as squared incisor arcade length & 0.8 & 2 \\
\hline Monkey Macaca mulatta & 6 & 14 & $\begin{array}{l}\text { Squared maximum grip size (the distance } \\
\text { between the thumb and distance finger) }\end{array}$ & 4 & 3 \\
\hline Man & 80 & 60 & Palmar surface of grip area & 3 & 4 \\
\hline Wapiti Cervus elaphus & 230 & 40 & Bite area measured from bite imprints on new grass & 1 & 5 \\
\hline Moose Alces alces & 434 & 25 & Bite area estimated as squared incisor arcade length & 0.05 & 2 \\
\hline Cattle Bos taurus & 700 & 80 & Bite area estimated as squared incisor arcade length & 1 & 6 \\
\hline Mean & & & & 2 & \\
\hline
\end{tabular}

Note. $M$ is body mass, $s_{\delta}$ is the estimated space scale (area) of one act of plant biomass consumption by the animal, $\delta \equiv s_{\delta} / l^{2}, l$ is linear body size, $l \equiv(M / \rho)^{1 / 3}, \rho=1 \mathrm{~g} \mathrm{~cm}^{-3}$. Sources: (1) Jordano, 2000; (2) Pérez-Barbería and Gordon, 2001; (3) Roy et al., 2000; (4) Flatt, 2000; (5) Jiang and Hudson, 1994; (6) Wallis de Vries, 1995.

dependence:

$\log _{\mathrm{e}} f=\log _{\mathrm{e}} B_{1} \delta+\left(\frac{2}{3}\right) \log _{\mathrm{e}} M$,

where $M$ and $f$ measured in grams correspond to $B_{1}$ measured in $\mathrm{g} \mathrm{cm}^{-2}$. The intercept $a \equiv \log _{\mathrm{e}} B_{1} \delta$ of the $\log -\log$ regression of $f$ on body mass $M$ gives therefore an independent estimate of the product $B_{1} \delta$.

Shipley et al. (1994) studied the dependence of maximum bite size $f_{\max }$ on body mass in mammalian herbivores with $M$ ranging from 1 to $1200 \mathrm{~kg}$. The scaling exponent was found to equal $0.71 \pm 0.04$, in close proximity with the theoretical value of 0.67 , Eqs. (1) and (18). The intercept $a$ was found to equal $-2.34 \pm 0.20$, which corresponds to $B_{1} d=e^{-2.34} \mathrm{~g} \mathrm{~cm}^{-2}=$ $0.096 \mathrm{~g} \mathrm{~cm}^{-2}$. Assuming $\delta \sim 2 \times 10^{-2}$ as estimated in Table 3 this gives $B_{1}=48 \mathrm{~kg} \mathrm{~m}^{-2}$.

In boreal forests, total biomass ranges from 6 to $40 \mathrm{~kg}$ dry weight $\mathrm{m}^{-2}$ (Whittaker and Likens, 1975), of which metabolically active biomass (bark, leaves (needles) and twigs) constitutes approximately 10-20\% (Whittaker and Marks, 1975). Assuming conservatively that water content is about $2 / 3$ of wet weight of the metabolically active biomass (Larcher, 1980), we obtain a maximum estimate for $B_{1}$ of $40 \times 0.2 \times 3=$ $24 \mathrm{~kg}$ fresh weight $\mathrm{m}^{-2}$, which agrees by the order of magnitude with the value of $48 \mathrm{~kg} \mathrm{~m}^{-2}$ obtained from the data of Shipley et al. (1994). Given the considerable uncertainty of all the parameters involved, the observed order-of-magnitude coincidence is remarkable. (Note also that some species analysed by Shipley et al. (1994) were tropical, and could be adapted to higher biomass values. This could produce an elevated estimate of $B_{1}$ as compared to the data for boreal zone).

Another possibility of testing Eq. (1) is provided by the comprehensive and elegant study of Wikelski et al. (1997). They described food consumption process in a grazing reptile, Galapagos marine iguana $\mathrm{Am}$ blyrhynchus cristatus, which feeds on marine algae. The data of Wikelski et al. are unique in containing independent estimates of all parameters entering Eq. (1) under a variety of conditions.

Iguanas were studied at two islands Santa Fe (SF) and Genovesa $(\mathrm{G})$ with considerably different algae biomass $B_{1 \mathrm{SF}} \approx 22 \mathrm{gdry}$ weight $\mathrm{m}^{-2}$ and $B_{1 \mathrm{G}} \approx$ $6.4 \mathrm{~g}$ dry weight $\mathrm{m}^{-2}$ (averaged over the studied period). On Santa Fe, the body mass of iguanas ranged from 137 to $2180 \mathrm{~g}$. The amount of algae eaten per bite, $f$, grew consistently with body size from 1.66 to $7.82 \mathrm{mg}$ dry weight. Using the six mass classes described by Wikelski et al. (1997, Table 2) on Santa $\mathrm{Fe}$, we obtained the following parameters of the regression $\log _{10} f=a_{\mathrm{SF}}+b_{\mathrm{SF}} \log _{10} M$ (both $f$ and $M$ measured in grams): an intercept $a_{\mathrm{SF}}=-3.95 \pm 0.22$ and a slope of $b_{\mathrm{SF}}=0.58 \pm 0.08( \pm$ S.D. $)\left(r^{2}=0.93\right)$, which is in close proximity to the expected value of $b=0.67$. On Genovesa the iguanas do not reach the maximum body size, presumably due to the lower food availability. For a restricted range of body mass from 108 to $670 \mathrm{~g}$ we obtained $a_{\mathrm{G}}=-4.58 \pm 0.43$ and $b_{\mathrm{G}}=0.52 \pm 0.17\left(r^{2}=0.70\right.$, six size classes $)$, with the theoretical value 0.67 falling within the uncertainty range of the estimated value. 
The mean masses of the iguanas (calculated as the geometric mean of minimum and maximum values at each island) were $M_{\mathrm{SF}} \sim 550 \mathrm{~g}\left(l_{\mathrm{SF}}=0.080 \mathrm{~m}\right)$ and $M_{\mathrm{G}} \sim 270 \mathrm{~g}\left(l_{\mathrm{G}}=0.063 \mathrm{~m}\right)$. The mean observed food intakes per bite by iguanas with mean mass are $f_{\mathrm{SF}}=$ $4.4 \times 10^{-3} \mathrm{~g}$ dry weight and $f_{\mathrm{G}}=4.8 \times 10^{-4} \mathrm{~g}$ dry weight. Theoretical (T) $f$ values predicted from Eq. (1) using $\delta=2 \times 10^{-2}$ (Table 3 ), $l_{\mathrm{SF}}, B_{1 \mathrm{SF}}$ and $l_{\mathrm{G}}, B_{1 \mathrm{G}}$ are $f_{\mathrm{SFT}}=2.8 \times 10^{-3} \mathrm{~g}$ dry weight and $f_{\mathrm{GT}}=5.1 \times$ $10^{-4} \mathrm{~g}$ dry weight. The relative difference between theoretical and observed values, $100 \times\left(f-f_{\mathrm{T}}\right) / f$, is $36 \%$ for Santa $\mathrm{Fe}$ and $-6 \%$ for Genovesa.

We conclude that the available empirical data quantitatively confirm not only the scaling exponent in the proposed relationship between $f$ and body size, Eq. (1), but also the proportionality of food intake per bite to the standing biomass. On Genovesa where plant biomass $B_{1}$ is low, the food intake per bite is significantly lower than that on Santa Fe. The agreement in absolute values between the theory and observations for iguanas also shows that our independent estimate of $\delta$ (Table 3), applies satisfactorily to a wide range of animals.

\subsection{Energy consumption by the largest plant-feeding animals}

Using the estimated parameters $\varepsilon_{1}^{2} s_{1} \sim 6 \times 10^{-6} \mathrm{~m}^{2}$, $l_{\max } \sim 0.74 \mathrm{~m}$ and $\delta \sim 0.02$, we can now estimate the share $\beta(l)$ of ecosystem's primary productivity allocated to plant-feeding animals from the five size classes described in Table 1. For each species we calculate energy consumption as the product $D_{\mathrm{sp}} R$ of species' population density $D_{\mathrm{sp}}$ and metabolic rate $R$ calculated from Nagy's relations (15) for birds and mammals. Energy consumptions of all species within the size group are then summed and divided by ecosystem's primary productivity $P_{1}$ (the last but one column in Table 1), to yield the observed value $\beta(l)$ for this size group.

The corresponding theoretical values $\beta(l)$ were calculated from Eq. (12). As already noted, the five size classes of Table 1 are distanced from each other by an approximately tenfold change in body mass (Holling, 1992). One can define the following mass intervals (1) 10 to $10^{2} \mathrm{~g}$; (2) $10^{2}$ to $10^{3} \mathrm{~g}$; (3) $10^{3}$ to $10^{4} \mathrm{~g}$; (4) $10^{4}$ to $10^{5} \mathrm{~g}$ and (5) $10^{5}$ to $10^{6} \mathrm{~g}$. Geometric mean masses calculated for each interval are $M_{1}=32 \mathrm{~g}, M_{2}=$

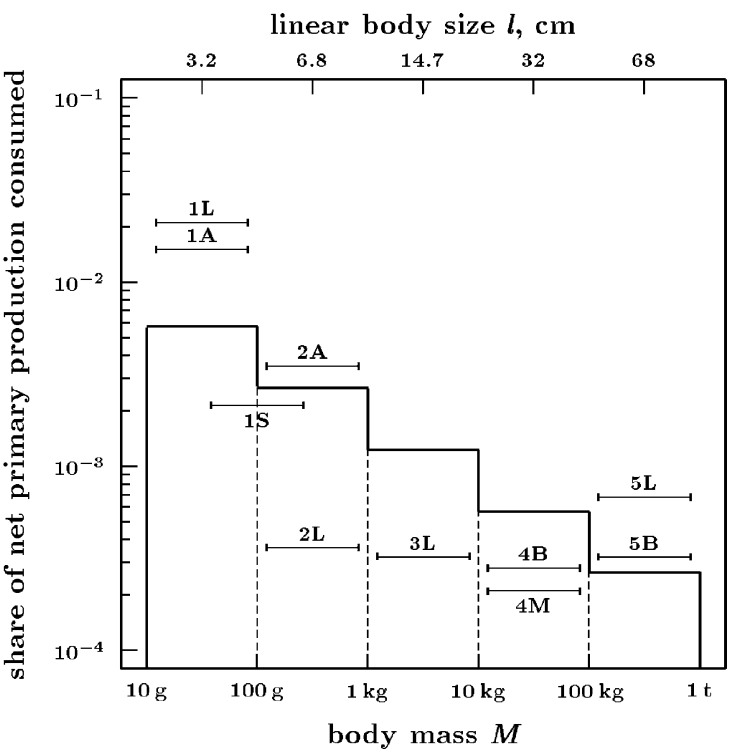

Fig. 3. Relative share $\beta(l)$ of net primary production consumed by plant-feeding organisms from different body size classes. The histogram (thick lines) shows theoretical distribution derived from Eq. (12) using estimates of the size-independent parameters $\varepsilon_{1}, s_{1}$ and $l_{\max }$ obtained in Section 6.1. Height of each histogram bar is equal to the cumulative energy consumption of all community's organisms with body size falling within the respective logarithmic interval. Thin lines marked with figures and letters denote the observed $\beta(l)$ values corresponding to size groups of Table 1 .

$320 \mathrm{~g}, M_{3}=3200 \mathrm{~g}, M_{4}=32 \mathrm{~kg}$ and $M_{5}=320 \mathrm{~kg}$, respectively. They are in approximate agreement with mean masses for each class shown in Table 1. As far as a tenfold increase in body mass corresponds to 2.15fold increase in body size, the coefficient $k$ in Eq. (12) was taken to be 2.15 .

Linear size $l$ was taken as the $1 / 3$ power of the geometric mean masses $M_{i}$ for each interval calculated above, that is, $l_{1}=3.2 \mathrm{~cm}, l_{2}=6.8 \mathrm{~cm}, l_{3}=14.7 \mathrm{~cm}$, $l_{4}=32 \mathrm{~cm}$ and $l_{5}=68 \mathrm{~cm}$ for $1 \mathrm{st}-5$ th intervals, respectively. The low scaling exponent in the $l-M$ relationship justifies the usage of the size class logarithmic midpoints instead of mean size values that differ somewhat from ecosystem to ecosystem, cf. Table 1, second column. Size group 2S (Eutamias sibiricus, $100 \mathrm{~g}$ ) falling exactly on the border between the mass intervals chosen, was treated separately, see Fig. 3.

In Fig. 3 a theoretical histogram of energy consumption $\beta(l)$ in the five logarithmic intervals of body mass is shown (thick lines). The height of histogram 
bar in the $i$-th interval is calculated from Eq. (1) using $l_{i}$ as defined above, $k=2.15$, and size-independent parameters $\varepsilon_{1}, s_{1}, l_{\max }$ and $\delta$ that were estimated in Section 6.1. Thin lines denote the observed values $\beta(l)$ of the relative share of consumption of ecosystem's primary productivity allocated to organisms from each size class in primary boreal forest ecosystems.

The theoretically predicted drop in $\beta(l)$ values by $l_{5} / l_{1}=21$ times is nicely matched by the $\sim 28$-fold drop observed between $1 \mathrm{~L}$ and $5 \mathrm{~L}$ size groups (the smallest and the largest mammals in the Lapland State Nature Reserve). We can see that this change is not distributed uniformly over all size classes. There is a much more significant drop (as compared to theoretically predicted one) in observed $\beta(l)$ values from the first and second to the third size class and practically no drop from the third to the fifth size class. Further research is needed to reveal whether this is a statistically significant pattern and what may be its ecological reasons.

Eq. (12) may provide clues for such an analysis. For example, as suggested by the data of Table 2 , the value of $\delta$ is larger in animals using hands (paws) for food gathering (man, monkey) than in animals whose foodgathering organ is mouth (e.g., ungulates). As suggested by Eq. (12), animals with lower $\delta$ values can be allowed a larger portion of community's energy flux. Such animals make relatively smaller bites consuming plant biomass in a more balanced manner. The abnormally low $\delta$ value of moose Alces alces (Table 2), could explain the elevated share of energy consumption as compared to the theoretical value which is allocated to this species in the boreal forest ecosystem (Fig. 3). By contrast, the brown bear Ursus arctos, another species from the largest body size interval, has a significantly lower consumption rate than the moose, cf. the population density data in Table 1 . This could be presumably explained by a larger $\delta$ value - when gathering plant food (e.g., corn), the bear is known to help itself with its paws seizing a large bundle of plant shoots at once (Yudin, 1987). This makes the area of a single food intake significantly larger than if the animal used its mouth only.

We believe that the most important result demonstrated by Fig. 3 is the order-of-magnitude coincidence between the theory and the data. As can be seen from Fig. 3, the difference between the observed and theoretically predicted values of $\beta$ does not ex- ceed one order of magnitude in any of the eleven size groups studied. That the flux of energy flow through organisms of a given body size can be predicted to the accuracy of one order of magnitude from parameters describing dominant plant species $\left(\varepsilon_{1}\right.$ and $\left.s_{1}\right)$, linear size of the largest community's heterotroph $l_{\max }$ and the relative area of food-gathering organs $\delta$ of the animals does, in our opinion, justify the efforts on further developing the proposed theoretical approach.

Using Fig. 3 as an example, it is possible to highlight an important theoretical point in the allometric studies of energy consumption distributions over body size. As a rule, in such studies one operates with $\log$-log regressions of the log-transformed variables of population density or biomass corresponding to logarithmic body size intervals. The resulting slopes of the $\log -\log$ regressions are used to judge about the energetic dominance of either larger or smaller organisms. However, such a procedure is not justified if the character of energy consumption change with body size has the form similar to that shown in Fig. 3. That is, when one observes a radical drop of energy consumption in the smallest body size interval followed by a relatively constant distribution over the larger body size intervals. As long as in the log-log regression all body size intervals have equal statistical weights, such a regression would mask the significant drop of $\beta(l)$ at the smaller body sizes and yield a shallow, close to zero slope determined by the relatively constant $\beta(l)$ values in the larger body size intervals. Judging from this slope alone, one could thus make an erroneous conclusion that in the community studied there is an approximate energetic equivalence of the differently sized organisms. In reality, in the case of Fig. 3 the smallest animals from the first size class claim about an order of magnitude larger energy flux than all the other size classes combined. A similar contradiction is exemplified by the study of Quintana et al. (2002), who reported that more stable aquatic communities of the Mediterranean salt marshes are characterised by shallower logarithmic slopes than unstable ones. At the same time Quintana et al. (2002) noted that in the stable ecosystems the smallest phytoplankters are most abundant, while the less stable ecosystems (with steeper logarithmic slopes) are dominated by relatively large species, which is in accordance with the predictions of our approach. 
This consideration suggests that the analysis of slopes in the log-log regressions can be misleading if not paralleled by an accurate analysis of the absolute shares of consumption claimed by organisms of different size.

\subsection{Energy consumption portrait of the whole community}

We have now seen that the largest plant-feeding heterotrophs (with body mass exceeding $10 \mathrm{~g}$ and linear body size exceeding $3 \mathrm{~cm}$ ) do not altogether consume more than $1-2 \%$ of the ecosystem's primary production (Fig. 3). As testified by the data discussed in Section 5.5, most organisms with body sizes not exceeding several millimetres are likely to be residents. For them we expect an approximately equitable distribution of energy consumption over body size intervals.

To estimate the share of community's energy consumption allocated to arthropods, we continue the theoretical histogram in Fig. 3 for two more logarithmic body mass intervals to the left, i.e., to the body mass interval from 0.1 to $1 \mathrm{~g}$ (geometric mean mass $0.32 \mathrm{~g}$ and linear size $l \sim 0.68 \mathrm{~cm})$. We assume that this is the smallest body size interval for travellers, for which Eq. (12) is expected to hold. From Eq. (12) we estimate that $\beta(l)$ for this interval is equal to 0.031 . Assuming that the body size of resident arthropods ranges from approximately $10^{-4}$ to $10^{-2} \mathrm{~m}$ (body mass from $10^{-6}$ to $1 \mathrm{~g}$ ) we obtain six logarithmic body mass intervals for the resident arthropods. Assuming that the share of energy consumption $\beta(l)$ in these intervals is constant and equals to the estimated 0.031 , we obtain that these organisms as a whole consume $(0.03 \times 6) \times 100 \%=$ $18 \%$ of the community's primary productivity.

The available observations support this conclusion. According to Coley and Barone (1996) who reviewed data on 46 tropical ecosystems, the mean share of consumption by herbivores on primary vegetation is about $11-14 \%$, of which insects claim the dominant portion. The data of Stork and Blackburn (1993) are also consistent with the obtained estimate. Judging from their Fig. 1e, the total arthropod biomass per hectare of forest is of the order of $B \sim 60 \mathrm{~kg} \mathrm{ha}^{-1}$. Mean primary productivity of tropical forests is $P_{1}$ $\sim 1 \mathrm{~W}^{-2}$ (Lieth, 1975). In order to obtain a $\beta$ value for arthropods of about $\beta \sim 0.2$, we need to assume that their mean mass-specific metabolic rate is about
$30 \mathrm{~W} \mathrm{~kg}^{-1}, \beta=r B / P_{1}$. The value of $r=30 \mathrm{~W} \mathrm{~kg}^{-1}$ is within the range of resting mass-specific metabolic rates reported for insects (Muthukrishnan and Pandian, 1987), although significantly larger than that for noninsect arthropods (Lighton et al., 2001), suggesting that the real consumption rate of arthropods can be lower than 0.2 .

We thus conclude that the largest heterotrophs (travellers) with linear size from $10^{-2}$ to $1 \mathrm{~m}$ consume $1-2 \%$ and the intermediate heterotrophs (resident) with linear body size from $10^{-4}$ to $10^{-2} \mathrm{~m}$ consume $10-20 \%$ of the ecosystem net primary productivity. The remaining 80-90\% should be therefore consumed by the smallest community's heterotrophs like bacteria, fungi and other microscopic organisms.

The largest share of consumption allocated to the smallest heterotrophs is independently confirmed by observations. As already mentioned, in stable ecosystems of open ocean and lakes the share of energy consumption by bacteria exceeds 90\% (Del Giorgio et al., 1997; Biddanda et al., 2001). The available data on soil bacteria agree with these figures. Clarholm and Rosswall (1980) report an annual bacterial productivity $P_{\text {bact }}=210 \mathrm{~g}$ dry weight $\mathrm{m}^{-2}$ per year in a boreal subarctic forest. Mean net primary productivity of boreal forests is $500 \mathrm{~g}$ wet weight $\mathrm{m}^{-2}$ per year (Lieth, 1975), which corresponds to about $330 \mathrm{~g}$ dry weight $\mathrm{m}^{-2}$ per year assuming a conservative estimate of water content of $2 / 3$ wet weight (Larcher, 1980). If one assumes the bacterial growth efficiency (BGE $\equiv$ bacterial production/(bacterial production + bacterial respiration) equal to 0.5 , we obtain $\beta_{\text {bact }}=210 / 330=$ 0.64 . As far as the commonly used $\mathrm{BGE}=0.5$ has been shown to be a gross overestimate, especially in stable ecosystems (Del Giorgio and Cole, 1998), the actual $\beta_{\text {bact }}$ should even exceed the estimated value of $64 \%$.

Direct assessment of microbial respiration in soil gives similar values. For boreal pine forests not affected by grazing, Ohtonen and Väre (1998) estimate microbial respiration as $33 \times 10^{-6} \mathrm{~g} \mathrm{C} \mathrm{h}^{-1}$ per gram soil organic matter at $20^{\circ} \mathrm{C}$. Organic matter in soils studied constitutes about $80 \%$ of soil dry weight (Pennanen et al., 1999), dry weight constitutes about $25 \%$ of total soil weight under studied conditions (Ohtonen and Väre, 1998; Stenstrøm et al., 2001) and soil density is about $1.5 \mathrm{~g} \mathrm{~cm}^{-3}$ (Stenstrøm et al., 2001). Taking also into account that the depth of 


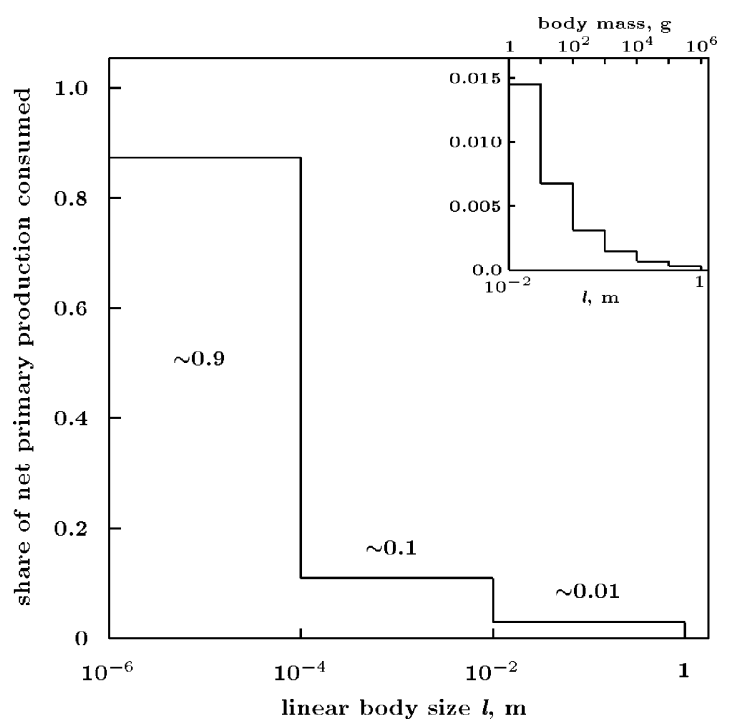

Fig. 4. Order-of-magnitude energy consumption portrait of a stable ecological community. The values $\beta(l)$ of the relative share of net primary production consumed by organisms from the two smallest body size intervals, $\beta(l) \sim 0.8-0.9$ for $10^{-6} \leq l \leq 10^{-4} \mathrm{~m}$ and $\beta(l) \sim 0.1-0.2$ for $10^{-6} \leq l \leq 10^{-4} \mathrm{~m}$, are estimated from the data available in the literature, see text. The inlet shows theoretical $\beta(l)$ values for the largest plant-feeding heterotrophs estimated from Eq. (1), cf. Fig. 3. Area enclosed by the large histogram is of the order of unity, area enclosed by the small histogram is of the order of 0.01 .

soil layer is about $1 \mathrm{~cm}$ (Ohtonen and Väre, 1998), we obtain from these figures for the rate of energy consumption by bacteria and fungi a value of $P_{\mathrm{m}} \sim$ $10^{-6} \mathrm{~g} \mathrm{C} \mathrm{cm}^{-2} \mathrm{~h}^{-1}$. Noting that burning $1 \mathrm{~g}$ organic $\mathrm{C}$ releases approx. $4.2 \times 10^{3} \mathrm{~J}$ we obtain for microbial respiration a value of $P_{\mathrm{m}} \sim 1.2 \mathrm{~W} \mathrm{~m}^{-2}$. This figure exceeds primary productivity of boreal forests $P_{1} \sim$ $0.37 \mathrm{~W} \mathrm{~m}^{-2}$ by more than threefold. We conclude that soil bacteria and fungi are able to consume $100 \%$ of primary productivity in 3-4 months, which corresponds to the vegetation season in the boreal zone. Pennanen et al. (1999) give similar values for mature pine and spruce forests $\left(22.2\right.$ and $39.2 \times 10^{-6} \mathrm{~g} \mathrm{C}$ $\mathrm{h}^{-1}$ per gram soil organic matter, respectively).

The resulting energy consumption portrait of a stable ecological community is shown in Fig. 4.

In this paper we provided a quantitative explanation for the low absolute values of energy consumption inherent to the largest terrestrial heterotrophs (travellers), $\beta(l) \sim 10^{-2}$, and its decrease with body size (see inlet in Fig. 4). The observed pattern of energy partitioning within the smaller size classes, i.e., among residents (bacteria, fungi, arthropods), can be further studied in the framework of the developed theoretical approach. Residents do not introduce fluctuations due to horizontal movements in and out ecosystem units, cf. Fig. 1. However, the fluctuations of plant biomass consumption introduced by residents, although apparently negligible as compared to those introduced by travellers, can also depend on body size, for example, due to dependence of individual lifespan on body size. Indeed, during the considered period $\tau_{1}$ of plant biomass turnover smaller organisms will have on average more generations than larger ones, which, in accordance with the law of large numbers, can make their cumulative consumption process more balanced than that of larger organisms, thus allowing them to consume more community's energy, Fig. 4.

In unstable environments the ecological restrictions on fluctuations of consumption are lessened and energy partitioning becomes more equitable. Microbial respiration in mature forests is significantly larger than in early successional forests or on a grassland (Pennanen et al., 1999; Imberger and Chiu, 2001). Similarly, the share of bacterial respiration in eutrophic aquatic systems drops by an order of magnitude (Biddanda et al., 2001). For example, Pennanen et al. (1999) indicate that microbial respiration is 1.5-2.5 times lower at early successional sites than in mature forests. If in mature forests the share of microbial energy consumption amounts to $80-90 \%$, on early successional sites it should be 30-50\%, leaving the remaining energy flux to be consumed by the larger heterotrophs. The share of consumption by heterotrophs of intermediate body sizes (arthropods) increases by several times in unstable environments. Coley and Barone (1996) note that on treefall gaps in tropical forests the consumption of net primary production by herbivores is $48 \%$ as compared to $14 \%$ on primary vegetation. (Treefall gaps represent local hotspots of succession process. Notably, the relative area covered by such rapidly changing habitats accounts for no more than $15 \%$ of a sustainable forest area (Coley and Barone, 1996)). On grasslands, insects may consume $20-25 \%$ of net primary productivity (Mitchell and Pfadt, 1974; Hewitt and Onsager, 1983). On pastures, about $40 \%$ of net primary productivity is consumed by cattle (Odum, 1971). 


\section{Conclusions}

A new theoretical approach for description of energy partitioning among differently sized organisms in ecological community has been presented. The assumption central to the developed theory is that natural ecological communities are organised in a way maximising the ecosystem stability, i.e., stability of the community itself and its local environment (Gorshkov, 1981, 1995).

The amount of metabolically active plant biomass per unit area is one of the most important community's characteristics, as it directly determines the power and character of local biochemical fluxes. We showed that large plant-feeding animals introduce substantial fluctuations of plant biomass, the magnitude of which grows rapidly with body size. To counteract this growth, the share of energy consumption $\beta(l)$ allocated to larger heterotrophs in a stable ecological community should be suppressed. We show that on average $\beta(l)$ drops inversely proportionally to the linear body size $l$ of the larger plant-feeding heterotrophs. In natural undisturbed ecosystems the largest terrestrial plant-feeding heterotrophs are allowed to consume no more than several tenths of per cent of net primary productivity.

As predicted by our approach, in unstable ecosystems, where environment is shaped by abiotic processes uncotrollable by the local biota, no ecological restrictions can be imposed on biotic environmental fluctuations. Consequently, in unstable ecosystems the community's energy flow can be distributed irregularly over differently sized animals, showing on average no dependence on body size.

We tested and confirmed the quantitative predictions of our theory using diverse sets of empirical data (Sections 5 and 6).

We show that pooling the data from ecosystems with different degrees of stability produces scaling exponents with little or no ecological meaning. Our results help to explain why different studies report that larger organisms consume more, less or equal amounts of energy than the smaller ones. The seemingly irregular patterns observed become consistent as soon as the environmental stability of the ecosystems studied is taken into account.

On a practical plane, the derived $\beta(l)$ distribution of energy consumption over body size is important for long-term conservation practices, as long as it allows to estimate the optimum population densities of the threatened species that can be sustained on a given territory without undermining long-term ecosystem stability.

Further theoretical research is needed to link the allometric $\beta(l)$ distribution to quantitative indices of environmental stability, like, for example, the rate of soil erosion. The dynamics of ecosystem degradation and environmental change can be then predicted from an instantaneous portrait of allometric distribution of energy consumption over organisms of different body sizes and its deviations from the natural sustainable $\beta(l)$ distribution.

At present human directly consumes about $10 \%$ of the global net primary productivity of the biosphere. (This includes food of man and cattle and consumption of wood (Gorshkov et al., 2000)). As is clear from Fig. 4 (inlet), this figure exceeds the energy consumption quota allocated to similarly-sized animals in environmentally stable ecosystems by two orders of magnitude. Expectedly, the terrestrial part of the biosphere is undergoing rapid environmental degradation. Further studies of the natural $\beta(l)$ distribution can be useful for elaborating strategies of optimisation of the man-biosphere interaction, with global environmental sustainability as the ultimate goal.

\section{Acknowledgements}

We are very grateful to $\mathrm{H}$. Ishii who generously shared his unpublished data on crown size and needle weight in old-growth Pseudotsuga menziesii with us. This work was partially supported by Russian Foundation for Fundamental Research, U.S. National Science Foundation, and the University of California Agricultural Experiment Station.

\section{Appendix A. Law of large numbers for photosynthesis}

We denote by $B_{1}$ the amount of metabolically active (edible) aboveground plant biomass per unit area, which includes plant phytomass (leaves, needles), tree cambium and various fruits and seeds. Metabolically active plant biomass is the preferred food source for most plant-feeding animals. 
Metabolically inactive biomass (wood, coarse roots) is produced much more slowly than metabolically active biomass. The latter accounts for the dominant part of the net primary productivity $P_{1}\left(\mathrm{~g} \mathrm{C} \mathrm{m}^{-2}\right.$ per year) (Whittaker and Marks, 1975; Kajimoto et al., 1999). The turnover time $\tau_{1}$ of the metabolically active plant biomass can be therefore estimated as $\tau_{1} \approx B_{1} / P_{1}$.

Photosynthesis of organic matter is performed by uncorrelated objects like leaves, needles, etc. The amount of metabolically active organic matter synthesised by one needle during time $\tau_{1}$ is proportional to the needle chlorophyll content and, consequently, to mean needle mass $m$ and can be written as Am. As far as the biochemistry of photosynthesis is the same for all needles, one can assume that the coefficient $A$ does not fluctuate from one needle to another. The fluctuating variable is the mass of individual needle $m_{i}$. For the metabolically active plant mass on territory $s_{1}$ we have:

$s_{1} \hat{B}_{1}=\sum_{i=1}^{N_{1}} A m_{i}, \quad s_{1} B_{1}=N_{1} A m$,

$m=\frac{1}{N_{1}} \sum_{i=1}^{N_{1}} m_{i}$,

where $N_{1}$ is the number of needles on area $s_{1}$ occupied by one tree, $\hat{B}_{1}$ is the random variable describing plant biomass on area $s_{1}$ and $B_{1}$ is its mean value. The random variable $s_{1} \hat{B}_{1}$ reflects the difference in plant mass between several areas $s_{1}$ or over several periods of time $\tau_{1}$ at the same area $s_{1}$. The variance of $s_{1} \hat{B}_{1}$ is

$$
\begin{aligned}
& \overline{\left(s_{1} \hat{B}_{1}-s_{1} B_{1}\right)^{2}} \\
& =\sum_{i=1}^{N_{1}} \overline{A\left(m_{i}-m\right)^{2}} \\
& =N_{1} A^{2} m^{2}+A^{2} \sum_{i, j}^{N_{1}} \overline{\left(m_{i}-m\right)\left(m_{j}-m\right)}=N_{1} A^{2} m^{2}
\end{aligned}
$$

In (A1.2) it is assumed that the relative variance of $m_{i}$ is of the order of unity, $\overline{\left(m_{i}-m\right)^{2}} / m^{2}=1$, to account for both random changes in needle mass (Karpov, 1983) and random change of their number $N_{1}$ (if a needle does not re-grow after falling, its mass can be formally taken as zero). The second term in the last but one equality of (A1.2) (squared correlation coefficient) equals zero, as long as functioning of separate needles and, consequently, changes in their mass are not mutually correlated.

For the relative variance of plant mass on area $s_{1}$ we have

$\varepsilon_{1}^{2} \equiv \frac{\overline{\left(s_{1} \hat{B}_{1}-s_{1} B_{1}\right)^{2}}}{s_{1}^{2} B_{1}^{2}}=\frac{1}{N_{1}}$

In accordance with the law of large numbers, the fluctuations of plant biomass due to photosynthesis are low, as far as photosynthesis is performed by a large number $N_{1}$ of mutually uncorrelated objects. In coniferous trees these objects are presumably needles. Individual needles can perform well even if their neighbours are destroyed, while any part of a single needle cannot function normally by itself if the remaining part is damaged. The linear size of one needle thus represents the radius of internal correlation of the photosynthesis process, beyond which the photosynthesising organs are uncorrelated. In foliaceous terrestrial plants and multicellular sea algae the radius of internal correlation is apparently much smaller than the size of one leaf, as far as normal functioning of a leaf is possible even if a substantial part of the leaf is removed (e.g., by a folivore). The corresponding number $N_{1}$ for foliaceous plants is therefore much larger than the total number of leaves.

\section{Appendix B. The probability distribution of the number of food intake acts on a given area}

To meet its metabolic requirements over a certain period of time, the animal performs $N$ acts of food intake that are randomly distributed over its feeding territory (home range) $S$. For any one act of food intake the probability $\vartheta$ of the event that this act was performed on a given area $s_{1} \leq S$ is equal to $\vartheta=s_{1} / S$. The probability $p(\hat{n})$ that exactly $\hat{n}$ acts of food intake were performed on area $s_{1}$ (after there had been $N$ acts of food intake on territory $S$ ) is thus described by the binomial distribution:

$p(\hat{n})=\frac{N !}{\hat{n} !(N-\hat{n}) !} \vartheta^{\hat{n}}(1-\vartheta)^{N-\hat{n}}$

The multiplier $\vartheta^{\hat{n}}$ gives the probability that $\hat{n}$ acts of food intake did all occur on $s_{1}$, while the multiplier 
$(1-\vartheta)^{N-\hat{n}}$ gives the probability that all the remaining $N-\hat{n}$ acts of food intake did not occur on $s_{1}$. The proportionality coefficient accounts for all possible combinations of food intake acts performed on and out of the area $s_{1}$.

The mean $n$ and variance $\sigma_{n}^{2}$ of the number $\hat{n}$ of food intake acts on area $s_{1}$ are retrieved from (A2.1) to be:

$n \equiv \sum_{\hat{n}=0}^{N} p(\hat{n}) \hat{n}=N \vartheta=N \frac{s_{1}}{S}$ $\sigma_{n}^{2} \equiv \sum_{\hat{n}=0}^{N} p(\hat{n})(\hat{n}-n)^{2}=n(1-\vartheta)=n\left(1-\frac{s_{1}}{S}\right)$

When $\vartheta=s_{1} / S \ll 1$ (highly mobile animals with large home ranges), the binomial probability distribution (A2.1) turns to Poisson distribution:

$p(\hat{n})=\frac{n^{\hat{n}}}{\hat{n} !} e^{-n}, \quad$ for which $\sigma_{n}^{2}=n$.

\section{Appendix C. Population densities $D$ (individual $\mathrm{km}^{-2}$ ) of some plant-feeding mammals-inherent inhabitants of boreal forests-in different regions of Eurasia}

Brown bear Ursus arctos

\begin{tabular}{|c|c|c|c|c|}
\hline Region & $\begin{array}{l}\text { Studied area } \\
\left(\mathrm{km}^{2}\right)\end{array}$ & $\begin{array}{l}D \\
\text { (individual } \mathrm{km}^{-2} \text { ) }\end{array}$ & $\begin{array}{l}\text { Comments on characteristics } \\
\text { of the study site }\end{array}$ & Source \\
\hline $\begin{array}{l}\text { Ukraine, the Carpathian } \\
\left(50^{\circ} \mathrm{N}, 24^{\circ} \mathrm{E}\right)\end{array}$ & 11,400 & 0.017 & Mountainous forests & 1 \\
\hline $\begin{array}{l}\text { Berezinsky Nature } \\
\text { Reserve, Byelorussia } \\
\left(53^{\circ} \mathrm{N}, 29^{\circ} \mathrm{E}\right)\end{array}$ & & 0.033 & $\begin{array}{l}\text { "Mature spruce and mixed forests" } \\
\text { are characterized as the preferred } \\
\text { habitats of the species }\end{array}$ & 2 \\
\hline $\begin{array}{l}\text { Nizhnesvirsky Nature } \\
\text { Reserve, Leningrad } \\
\text { region }\left(60^{\circ} \mathrm{N}, 30^{\circ} \mathrm{E}\right)\end{array}$ & 359 & 0.028 & $\begin{array}{l}\text { Habitats characterized as } \\
\text { "favorable for the species, with a } \\
\text { stable and diverse food resource } \\
\text { base". Dominance of plants in the } \\
\text { diet stressed }\end{array}$ & 3 \\
\hline $\begin{array}{l}\text { Krasnodar region } \\
\left(45^{\circ} \mathrm{N}, 39^{\circ} \mathrm{E}\right), \text { the } \\
\text { Caucasus }\end{array}$ & 11,600 & 0.027 & $\begin{array}{l}\text { Average over } 12 \text { years of } \\
\text { observations. During migration, } \\
\text { short-term local population } \\
\text { densities of nine individual } \mathrm{km}^{-2} \\
\text { were recorded }\end{array}$ & 4 \\
\hline $\begin{array}{l}\text { Vologda region }\left(59^{\circ} \mathrm{N},\right. \\
\left.40^{\circ} \mathrm{E}\right)\end{array}$ & $\sim 100,000$ & 0.03 & $\begin{array}{l}\text { Commonness of the species in } \\
\text { spruce forests is noted; } 88 \% \text { of } \\
\text { trees used by bears as markers of } \\
\text { their individual territories are } \\
\text { spruce trees }\end{array}$ & 5 \\
\hline $\begin{array}{l}\text { Pinezhsky Nature } \\
\text { Reserve, Arkhangelsk } \\
\text { region }\left(65^{\circ} \mathrm{N}, 42^{\circ} \mathrm{E}\right)\end{array}$ & 412 & 0.04 & $\begin{array}{l}\text { Spruce-dominated forests (Picea } \\
\text { obovata). } 73 \% \text { of trees used by } \\
\text { bears as markers of their individual } \\
\text { territories are spruce trees. } \\
\text { Dominance of plants in the diet is } \\
\text { stressed }\end{array}$ & 6 \\
\hline
\end{tabular}


Appendix C (Continued)

\begin{tabular}{|c|c|c|c|c|}
\hline Region & $\begin{array}{l}\text { Studied area } \\
\left(\mathrm{km}^{2}\right)\end{array}$ & $\begin{array}{l}D \\
\text { (individual } \mathrm{km}^{-2} \text { ) }\end{array}$ & $\begin{array}{l}\text { Comments on characteristics } \\
\text { of the study site }\end{array}$ & Source \\
\hline Armenia $\left(40^{\circ} \mathrm{N}, 45^{\circ} \mathrm{E}\right)$ & 2,500 & 0.05 & $\begin{array}{l}\text { Mountainous forests, optimal habitats } \\
\text { of the subspecies } U \text {. a. syriacus }\end{array}$ & 7 \\
\hline Kirov region $\left(59^{\circ} \mathrm{N}, 50^{\circ} \mathrm{E}\right)$ & $\sim 30,000$ & 0.025 & $\begin{array}{l}\text { Forests dominated by Picea obovata, } \\
\text { Abies sibirica and Larix sukaczewii }\end{array}$ & 8 \\
\hline $\begin{array}{l}\text { The Bashkir Nature Reserve; } \\
\text { Bashkir Autonomous } \\
\text { Republic }\left(54^{\circ} \mathrm{N}, 56^{\circ} \mathrm{E}\right)\end{array}$ & 220 & 0.15 & $\begin{array}{l}\text { Broad-leaf and pine forests of the } \\
\text { Ural mountains }\end{array}$ & 9 \\
\hline $\begin{array}{l}\text { Alma-Ata Nature Reserve } \\
\left(43^{\circ} \mathrm{N}, 77^{\circ} \mathrm{E}\right), \text { Kazakhstan }\end{array}$ & 250 & 0.1 & $\begin{array}{l}\text { Tien Shan mountains, population } \\
\text { density is characterized as stable; } \\
\text { dominance of plants in the diet is } \\
\text { stressed }\end{array}$ & 10 \\
\hline \multirow[t]{4}{*}{ Altaysky region $\left(53^{\circ} \mathrm{N}, 84^{\circ} \mathrm{E}\right)$} & & & 4-7 years of observations: & \multirow[t]{4}{*}{11} \\
\hline & 900 & 0.46 & Sumultinsky game reserve & \\
\hline & 1,033 & 0.15 & Ininsky game reserve & \\
\hline & 2,413 & 0.017 & Kosh-Agachsky game reserve & \\
\hline $\begin{array}{l}\text { Tomsk region }\left(57^{\circ} \mathrm{N}, 85^{\circ} \mathrm{E}\right) \\
\text { and Krasnoyarsk region } \\
\left(56^{\circ} \mathrm{N}, 93^{\circ} \mathrm{E}\right)\end{array}$ & 4,900 & 0.024 & $\begin{array}{l}\text { Population density was determined } \\
\text { by several methods: marking } \\
\text { individual territories of bears; } \\
\text { collecting information from hunters; } \\
\text { registration of footprints and tracing } \\
\text { of individual bears; air studies of } \\
\text { snow footprints in spring. Dominance } \\
\text { of plants in the diet stressed }\end{array}$ & 12 \\
\hline Irkutsk region $\left(52^{\circ} \mathrm{N}, 104^{\circ} \mathrm{E}\right)$ & 9,700 & 0.013 & See comments on the Tomsk region & 12 \\
\hline \multirow[t]{3}{*}{$\begin{array}{l}\text { The Buryat Autonomous } \\
\text { Republic }\left(52^{\circ} \mathrm{N}, 107^{\circ} \mathrm{E}\right)\end{array}$} & \multirow[t]{3}{*}{200,873} & 0.009 & $\begin{array}{l}\text { Mean for the bear habitats in the } \\
\text { republic }\end{array}$ & \multirow[t]{3}{*}{13} \\
\hline & & 0.07 & Barguzin Nature Reserve & \\
\hline & & 0.04 & Baikal Nature Reserve & \\
\hline $\begin{array}{l}\text { Region of the Baikal Lake } \\
\left(53^{\circ} \mathrm{N}, 110^{\circ} \mathrm{E}\right)\end{array}$ & 60,000 & 0.016 & $\begin{array}{l}\text { Population density is dependent } \\
\text { upon yearly yields of cedar cones. } \\
\text { Short-term population densities of } \\
\text { the order of } 0.5 \text { individual } \mathrm{km}^{-2} \\
\text { were recorded in areas of elevated } \\
\text { yield of cedar cones and berries. } \\
\text { These are characterized as extreme }\end{array}$ & 14 \\
\hline Chita region $\left(52^{\circ} \mathrm{N}, 113^{\circ} \mathrm{E}\right)$ & 2,100 & 0.008 & See comments on the Tomsk region & 12 \\
\hline $\begin{array}{l}\text { The Yakut Autonomous } \\
\text { Republic }\left(62^{\circ} \mathrm{N}, 130^{\circ} \mathrm{E}\right)\end{array}$ & 2,100 & 0.009 & $\begin{array}{l}\text { Mountainous and dark coniferous } \\
\text { taiga forests are characterized by } \\
\text { maximum population density of the } \\
\text { species (figures shown). In the other } \\
\text { types of habitats population density } \\
\text { is reported to be several times lower }\end{array}$ & 15 \\
\hline
\end{tabular}


Appendix C (Continued)

\begin{tabular}{|c|c|c|c|c|}
\hline Region & $\begin{array}{l}\text { Studied area } \\
\left(\mathrm{km}^{2}\right)\end{array}$ & $\begin{array}{l}D \\
\text { (individual } \mathrm{km}^{-2} \text { ) }\end{array}$ & $\begin{array}{l}\text { Comments on characteristics } \\
\text { of the study site }\end{array}$ & Source \\
\hline $\begin{array}{c}\text { Khabarovsk krai and Amurs- } \\
\text { kaya oblast }\left(48^{\circ} \mathrm{N}, 135^{\circ} \mathrm{E}\right)\end{array}$ & 18,500 & 0.008 & See comments on the Tomsk region & 12 \\
\hline Sakhalin $\left(47^{\circ} \mathrm{N}, 143^{\circ} \mathrm{E}\right)$ & 3,700 & 0.035 & See comments on the Tomsk region & 12 \\
\hline $\begin{array}{l}\text { Kamchatka Peninsula } \\
\left(56-60^{\circ} \mathrm{N}, 159^{\circ} \mathrm{E}\right)\end{array}$ & 25,000 & 0.032 & See comments on the Tomsk region & 12 \\
\hline Mean & & 0.058 & & \\
\hline
\end{tabular}

Note. Geographic coordinates correspond to administrative centres of the regions studied. Regions are ranged from West to East. Unless otherwise stated, the regions are in Russia. Sources: (1) Slobodyan, 1987; (2) Lavov, 1987; (3) Grachev, 1987; (4) Kudaktin, 1987; (5) Rukovsky, 1987; (6) Rykov, 1987; (7) Tikhonov, 1987; (8) Pavlov, 1987; (9) Loskutov, 1987; (10) Zhiryakov, 1987; (11) Berezin, 1990; (12) Dunishenko, 1987; (13) Smirnov et al., 1987; (14) Vinokurov and Mordosov, 1987; (15) Ustinov and Dvoryadkin, 1987.

Additional data on Ursus arctos population density:

Dunishenko (1987) states that the mean population density of brown bears in Siberia is 0.012 individual $\mathrm{km}^{-2}$ and 0.021 individual $\mathrm{km}^{-2}$ in most favourable habitats. These figures are compared to mean population density in Kazakhstan $\left(0.025\right.$ individual $\left.\mathrm{km}^{-2}\right)$ and centre of the European part of the USSR (0.025 individual $\mathrm{km}^{-2}$ ) (Dunishenko, 1987).

Pikunov (1987) and his coworkers studied population numbers of the brown bears in the mountainous forests of the Southern Far East by establishing 36 study plots in habitats typical for the species with a total area of $4500 \mathrm{~km}^{2}$. The highest population density ever recorded was 0.36 individual $\mathrm{km}^{-2}$. It was observed in autumn, when bears from a large territory concentrated for a short time in a local area characterised by a particularly high yield of cedar cones. It is clear that such figures cannot be used as a reference for sustainable population densities, cf. discussion in Section 5.2. 
Roe deer Capreolus capreolus

\begin{tabular}{|c|c|c|c|c|}
\hline Region & $\begin{array}{l}\text { Studied } \\
\text { area }\left(\mathrm{km}^{2}\right)\end{array}$ & $\begin{array}{l}D \\
\text { (individual } \mathrm{km}^{-2} \text { ) }\end{array}$ & $\begin{array}{l}\text { Comments on characteristics of } \\
\text { the study site }\end{array}$ & $\begin{array}{l}\text { Source } \\
\text { Source }\end{array}$ \\
\hline $\begin{array}{l}\text { Alma-Ata Nature Reserve } \\
\left(43^{\circ} \mathrm{N}, 77^{\circ} \mathrm{E}\right), \text { Kazakhstan }\end{array}$ & 250 & 4.7 & $\begin{array}{l}\text { Tien Shan mountains, } \\
\text { population density is } \\
\text { characterised as "rather high" }\end{array}$ & 1 \\
\hline \multirow[t]{3}{*}{$\begin{array}{l}\text { Novosibirsk region }\left(55^{\circ} \mathrm{N} \text {, }\right. \\
\left.83^{\circ} \mathrm{E}\right)\end{array}$} & 55,300 & 0.11 & $\begin{array}{l}\text { First-rate habitats (deciduous } \\
\text { forests, river valleys, meadows) }\end{array}$ & 2 \\
\hline & 32,000 & 0.08 & $\begin{array}{l}\text { Second-rate habitats (pine and } \\
\text { deciduous forests) }\end{array}$ & \\
\hline & 29,600 & 0.05 & $\begin{array}{l}\text { Third-rate habitats (northern } \\
\text { forests of the region and steppe) }\end{array}$ & \\
\hline \multirow[t]{4}{*}{ Altaysky region $\left(53^{\circ} \mathrm{N}, 84^{\circ} \mathrm{E}\right)$} & & & 4-7 years of observations: & 3 \\
\hline & 900 & 0.17 & Sumultinsky game reserve & \\
\hline & 1,033 & 0.22 & Ininsky game reserve & \\
\hline & 2,413 & 0.72 & Kosh-Agachsky game reserve & \\
\hline \multirow{4}{*}{$\begin{array}{l}\text { Northern part of the Altai } \\
\text { Mountains }\end{array}$} & $\sim 10,000$ & 3.5 & Birch-fir forests & 4 \\
\hline & & 2 & Pine-birch forests & \\
\hline & & 1 & Fir-birch forests & \\
\hline & & 0.4 & Other habitats & \\
\hline Vitim plateau $\left(49^{\circ} \mathrm{N}, 102^{\circ} \mathrm{E}\right)$ & $\sim 1,000$ & 0.12 & $\begin{array}{l}\text { Most numerous wild ungulate in } \\
\text { the region }\end{array}$ & 5 \\
\hline Irkutsk region $\left(52^{\circ} \mathrm{N}, 104^{\circ} \mathrm{E}\right)$ & 4,000 & 0.34 & $\begin{array}{l}\text { Estimate obtained for areas } \\
\text { where population density of roe } \\
\text { deer is high enough to consider } \\
\text { the possibility of industrial } \\
\text { hunting }\end{array}$ & 6 \\
\hline Mean & & 1.0 & & \\
\hline
\end{tabular}

Note. Geographic coordinates correspond to administrative centres of the regions studied. Regions are ranged from West to East. Unless otherwise stated, the regions are in Russia. Sources: (1) Zhiryakov, 1987; (2) Tsarev, 1966; (3) Berezin, 1990; (4) Tsybulin, 1990; (5) Lavov, 1966; (6) Murashov et al., 1990. 
Moose Alces alces

\begin{tabular}{|c|c|c|c|c|}
\hline Region & $\begin{array}{l}\text { Studied } \\
\text { area }\left(\mathrm{km}^{2}\right)\end{array}$ & $\begin{array}{l}D \\
\text { (individual } \mathrm{km}^{-2} \text { ) }\end{array}$ & $\begin{array}{l}\text { Comments on characteristics of } \\
\text { the study site }\end{array}$ & $\begin{array}{l}\text { Source } \\
\text { Source }\end{array}$ \\
\hline $\begin{array}{l}\text { Volgograd region } \\
\left(48^{\circ} \mathrm{N}, 45^{\circ} \mathrm{E}\right)\end{array}$ & 240,000 & 0.2 & $\begin{array}{l}\text { Population density of } \\
0.2 \text { individual } \mathrm{km}^{-2} \text { is } \\
\text { characterised as normal for the } \\
\text { species. Population density of } \\
0.6 \text { individual km } \\
\text { as too high and leading to } \\
\text { degradation of forest ecosystems }\end{array}$ & 1 \\
\hline $\begin{array}{l}\text { Tomsk region, Pudino } \\
\left(58^{\circ} \mathrm{N}, 79^{\circ} \mathrm{E}\right)\end{array}$ & $\sim 1,000$ & 0.09 & $\begin{array}{l}\text { Population density characterised as } \\
\text { "stable and relatively high" }\end{array}$ & 2 \\
\hline \multirow[t]{3}{*}{$\begin{array}{l}\text { Novosibirsk region } \\
\quad\left(55^{\circ} \mathrm{N}, 83^{\circ} \mathrm{E}\right)\end{array}$} & 47,200 & 0.09 & $\begin{array}{l}\text { First-rate habitats (deciduous } \\
\text { riparian forests, pine forests of the } \\
\text { central and southern part of the } \mathrm{Ob} \\
\text { river basin) }\end{array}$ & 3 \\
\hline & 41,300 & 0.05 & $\begin{array}{l}\text { Second-rate habitats (coniferous } \\
\text { forests of the northern part of the } \\
\text { Ob river basin) }\end{array}$ & \\
\hline & 29,500 & 0.02 & Third-rate habitats (bogs) & \\
\hline \multirow[t]{4}{*}{$\begin{array}{l}\text { Altaysky region } \\
\left(53^{\circ} \mathrm{N}, 84^{\circ} \mathrm{E}\right)\end{array}$} & & & $\begin{array}{l}\text { 4-7 years of observations: } \\
\text { population density characterised as } \\
\text { "sufficiently high" }\end{array}$ & 4 \\
\hline & 900 & 0.08 & Sumultinsky game reserve & \\
\hline & 1,033 & 0.07 & Ininsky game reserve & \\
\hline & 1,780 & 0.03 & Shavlinsky game reserve & \\
\hline \multirow[t]{4}{*}{$\begin{array}{l}\text { Krasnoyarsk region } \\
\quad\left(56^{\circ} \mathrm{N}, 93^{\circ} \mathrm{E}\right)\end{array}$} & $\sim 100,000$ & 0.35 & $\begin{array}{l}\text { Agricultural ecosystems, birch and } \\
\text { pine forests, population density } \\
\text { characterised as "especially high" }\end{array}$ & 5 \\
\hline & & 0.25 & Secondary forests & \\
\hline & & 0.11 & $\begin{array}{l}\text { Pine woods of the forest-steppe } \\
\text { zone }\end{array}$ & \\
\hline & & 0.06 & $\begin{array}{l}\text { Predominantly dark coniferous } \\
\text { forests }\end{array}$ & \\
\hline $\begin{array}{l}\text { Irkutsk region } \\
\qquad\left(52^{\circ} \mathrm{N}, 104^{\circ} \mathrm{E}\right)\end{array}$ & 4,000 & 0.09 & $\begin{array}{l}\text { Estimate obtained for areas where } \\
\text { population density of moose is } \\
\text { high enough to consider the } \\
\text { possibility of industrial hunting }\end{array}$ & 6 \\
\hline Mean & & 0.11 & & \\
\hline
\end{tabular}

Note. Geographic coordinates correspond to administrative centres of the regions studied. Regions are ranged from West to East. All regions are in Russia. Sources: (1) Pavlinov, 1990; (2) Shubin, 1990; (3) Tsarev, 1966; (4) Berezin, 1990; (5) Mirutenko, 1990; (6) Murashov et al., 1990. 


\section{References}

Adamovitch, V.L., Vatolin, B.A., 1973. Distribution of elk in the Bryansk region and damage to forests by it. Soviet J. Ecol. 4, 426-430.

Agustí, S., Kalff, J., 1989. The influence of growth conditions on the size dependence of maximal algal density and biomass. Limnol. Oceanogr. 34, 1104-1108.

Alexander, R.Mc.N., Maloiy, G.M.O., 1989. Locomotion of African mammals. Symp. Zool. Soc. Lond. 61, 163180.

Bailey, D.W., Gross, J.E., Laca, E.A., Rittenhouse, L.R., Coughenour, M.B., Swift, D.M., Sims, P.L., 1996. Mechanisms that result in large herbivore grazing distribution patterns. J. Range Manage. 49, 386-400.

Basset, Y., Aberlenc, H.-P., Barrios, H., Curletti, G., Bérenger, J.M., Vesco, J.-P., Causse, P., Haug, A., Hennion, A.-S., Lesobre, L., Marquès, F., O'Meara, R., 2001. Stratification and diel activity of arthropods in a lowland rainforest in Gabon. Biol. J. Linn. Soc. 72, 585-607.

Belgrano, A., Allen, A.P., Enquist, B.J., Gillooly, F.J., 2002. Allometric scaling of maximum population density: a common rule for marine phytoplankton and terrestrial plants. Ecol. Lett. 5, 611-613.

Berezin, A.E., 1990. Protection and rational exploitation of the animal world in the game reserves of the Western Siberia. In: Animal Resources of Siberia. Game Birds and Mammals. Collected Scientific Papers. Nauka (Siberian Branch), Novosibirsk, pp. 143-145 (in Russian).

Berezin, A.V., 2003. Ecology of hares in the Omsk region. In: Orlov, V.N. (Ed.), Teriofauna of Russia and Adjacent Territories (VIIth Meeting of the Teriological Society). Proceedings of the International Meeting, 6-7 February, 2003, Moscow, Teriological Society, p. 38.

Berg, H.C., 1996. Symmetries in bacterial motility. Proc. Natl. Acad. Sci. U.S.A. 93, 14225-14228.

Berrigan, D., Lighton, J.R.B., 1993. Bioenergetic and kinematic consequences of limblessness in larval Diptera. J. Exp. Biol. 179, 245-259.

Biddanda, B., Ogdahl, M., Cotner, J., 2001. Dominance of bacterial metabolism in oligotrophic relative to eutrophic waters. Limnol. Oceanogr. 46, 730-739.

Blackburn, T.M., Gaston, K.J., 1996. Abundance-body size relation-ships: the area you census tells you more. OIKOS 75 , 303-309.

Blackburn, T.M., Brown, V.K., Doube, B.M., Greenwood, J.D., Lawton, J.H., Stork, N.E., 1993. The relationship between abundance and body size in natural animal assemblages. J. Anim. Ecol. 62, 519-528.

Blackburn, T.M., Harvey, P.H., Pagel, M.D., 1990. Species number, population density and body size relationships in natural communities. J. Anim. Ecol. 59, 335-345.

Bobkova, K.S., Galenko, E.P. (Eds.), 2001. Bioproduction Process in Forest Ecosystems of the North. Nauka, St. Petersburg (in Russian).

Bobyr, G.Ya., 1987. The behaviour of brown bear in the mountains of the Western Caucasus. In: Yudin, B.S. (Ed.), Ecology of
Bears. Nauka (Siberian Branch), Novosibirsk, pp. 126-134 (in Russian).

Bormann, F.N., Likens, G.E., 1979. Pattern and Process in A Forested Ecosystem. Springer-Verlag, New York, 253 pp.

Bragg, D.C., 2001. A local basal area adjustment for crown width prediction. North. J. Appl. Forest. 18, 22-28.

Brody, S., 1945. Bioenergetics and Growth. Reinhold Publishing Corporation, New York, 1023 pp.

Brown, J.H., Gillooly, J.F., 2003. Ecological food webs: highquality data facilitate theoretical unification. Proc. Natl. Acad. Sci. U.S.A. 100, 1467-1468.

Brown, J.H., Maurer, B.A., 1986. Body size, ecological dominance and Cope's rule. Nature 324, 248-250.

Brown, J.H., Nicoletto, P.F., 1991. Spatial scaling of species composition: body masses of North American land mammals. Am. Nat. 138, 1478-1512.

Bryant, D., Nielsen, D., Tangley, L., 1997. The Last Frontier Forests: Ecosystems and Economies on the Edge. World Resources Institute, Washington, DC, $42 \mathrm{pp}$.

Clarholm, M., Rosswall, T., 1980. Biomass and turnover of bacteria in a forest soil and a peat. Soil Biol. Biochem. 12, 49-57.

Cohen, J.E., Jonsson, T., Carpenter, S.R., 2003. Ecological community description using the food web, species abundance, and body size. Proc. Natl. Acad. Sci. U.S.A. 100, 1781-1786.

Cohen, Y., Pastor, J., Moen, R., 1999. Bite, chew, and swallow. Ecol. Model. 116, 1-14.

Coley, P.D., Barone, J.A., 1996. Herbivory and plant defenses in tropical forests. Annu. Rev. Ecol. Syst. 27, 305-335.

Cowling, R., Kerley, G., 2002. Impacts of elephants on the flora and vegetation of subtropical thicket in the Eastern Cape. In: Kerley, G., Wilson, S., Massey, A. (Eds.), Elephant Conservation and Management in the Eastern Cape. Workshop Proceedings. Terrestrial Ecology Research Unit, University of Port Elizabeth, Port Elisabeth, pp. 55-72.

Damuth, J., 1981. Population density and body size in mammals. Nature 290, 699-700.

Damuth, J., 1987. Interspecific allometry of population density in mammals and other animals: the independence of body mass and population energy use. Biol. J. Linn. Soc. 31, 193-246.

Damuth, J., 1993. Cope's rule, the island rule and the scaling of mammalian population density. Nature $365,748-750$.

Damuth, J., 1994. No conflict among abundance rules. Trends Ecol. Evol. 9, 487.

DeAngelis, D.L., 1980. Energy flow, nutrient cycling and ecosystem resilience. Ecology 61, 764-771.

Del Giorgio, P.A., Cole, J.J., 1998. Bacterial growth efficiency in natural aquatic systems. Ann. Rev. Ecol. Syst. 29, 503-541.

Del Giorgio, P.A., Cole, J.J., Cimbleris, A., 1997. Respiration rates in bacteria exceed phytoplankton production in unproductive aquatic systems. Nature 385, 148-151.

Døckersmith, I.C., Giardina, C.P., Sanford Jr., R.L., 1999. Persistence of tree related patterns in soil nutrients following slash-and-burn disturbance in the tropics. Plant Soil 209, 137156.

Dodds, P.S., Rothman, D.H., Weitz, J.S., 2001. Re-examination of the "3/4-law" of metabolism. J. Theor. Biol. 209, 9-27, doi:10.1006/jtbi.2000.2238. 
Dunishenko, Y.M., 1987. Distribution and population number of the brown bear in Siberia and Far East. In: Yudin, B.S. (Ed.), Ecology of Bears. Nauka (Siberian Branch), Novosibirsk, pp. 45-51 (in Russian).

Ernest, S.K.M., Brown, J.H., 2001. Homeostasis and compensation: the role of species and resources in ecosystem stability. Ecology 82, 2118-2132.

Evans, H.F., Jukes, M.R., 2000. The role of niche availability as a factor determining the diversity and abundance of invertebrates on scots pine, Pinus sylvestris. Invest. Agr.: Sist. Recur. For.: Fuera de Series no. 1-2000, pp. 273-295.

Farrar, J.F., 1976. The lichen as an ecosystem: observation and experiment. In: Brown, D.H., Hawksworth, D.L., Bayley, R.H. (Eds.), Lichenology: Progress and Problems. Academic Press, New York, pp. 385-406.

Flatt, A.E., 2000. Grasp. BUMC Proceedings, vol. 13. pp. 343-348.

Gaedke, U., 1993. Ecosystem analysis based on biomass size distributions: a case study of a plankton community in a large lake. Limnol. Oceanogr. 38, 112-127.

Ghilarov, M.S., 1967. Abundance, biomass and vertical distribution of soil animals in different zones. In: Petrusewicz, K. (Ed.), Secondary Productivity of Terrestrial Ecosystems. Panstwowe Wydawnicto Nankowe, Warsaw, pp. 611-629.

Gorshkov, V.G., 1981. The distribution of energy flows among the organisms of different dimensions. Zh. Obsch. Biol. 42, 417-429 (in Russian).

Gorshkov, V.G., 1995. Physical and Biological Bases of Life Stability. Man, Biota, Environment. Springer-Verlag, Berlin, 340 pp.

Gorshkov, V.G., Gorshkov, V.V., Makarieva, A.M., 2000. Biotic Regulation of the Environment: Key Issue of Global Change. Springer-Verlag, London, $367 \mathrm{pp}$.

Grachev, Y.A., 1987. Brown bear in the Nizhnesvirsky Nature Reserve. In: Yudin, B.S. (Ed.), Ecology of Bears. Nauka (Siberian Branch), Novosibirsk, pp. 23-27 (in Russian).

Greenewalt, C.H., 1975. The flight of birds. Trans. Am. Phil. Soc. $65,1-67$.

Greenwood, J.D., Gregory, R.D., Harris, S., Morris, P.A., Yalden, D.W., 1996. Relations between abundance, body size and species number in British birds and mammals. Phil. Trans. R. Soc. Lond. B 351, 265-278.

Griffiths, D., 1992. Size, abundance and energy use in communities. J. Anim. Ecol. 61, 307-315.

Grodzinski, W., 1971. Food consumption of small mammals in the Alaskan taiga forest. Ann. Zool. Fennici 8, 133-136.

Gross, J.E., Hobbs, N.T., Wunder, B.A., 1993. Independent variables for predicting intake rate of mammalian herbivores: biomass density, plant density, or bite size? OIKOS 68, 75-81.

Haila, Y., 1988. Calculating and miscalculating density: the role of habitat geometry. Ornis Scand. 19, 88-92.

Hanks, L.M., Millar, J.G., Paine, T.D., 1996. Body size influences mating success of the Eucalyptus longhorned borer (Coleoptera: Cerambycidae). J. Insect Behav. 9, 369-382.

Hanley, T.A., 1982. The nutritional basis for food selection by ungulates. J. Range Manage. 36, 146-151.

Harvey, P.H., Lawton, J.H., 1986. Patterns in three dimensions. Nature 324, 212.
Haskell, J.P., Ritchie, M.E., Olff, H., 2002. Fractal geometry predicts varying body size relationships for mammal and bird home ranges. Nature 418, 527-530.

Haukioja, E., Koricheva, J., 2000. Tolerance to herbivory in woody versus herbaceous plants. Evol. Ecol. 14, 551-562.

Heinonsalo, J., Jørgensen, K.S., Sen, R., 2001. Microcosm-based analyses of Scots pine seedling growth, ectomycorrhizal fungal community structure and bacterial carbon utilization profiles in boreal forest humus and underlying illuvial mineral horizons. FEMS Microbiol. Ecol. 36, 73-84.

Hemmingsen, A., 1960. Energy metabolism as related to body size and respiratory surfaces, and its evolution. Rep. Steno. Mem. Hosp. 9, 1-110.

Hewitt, G.B., Onsager, J.A., 1983. Control of grasshoppers on rangeland in the United States-a perspective. J. Range Manage. 36, 202-207.

Hijii, N., 1984. Arboreal arthropod fauna in a forest. II. Presumed community structures based on biomass and number of arthropods in a Chamaecyparis obtusa Plantation. Jpn. J. Ecol. 34, 187-193.

Hill, N.A., Häeder, D.-P., 1997. A biased random walk model for the trajectories of swimming micro-organisms. J. Theor. Biol. 86, 503-526.

Holling, C.S., 1992. Cross-scale morphology, geometry, and dynamics of ecosystems. Ecol. Monogr. 62, 447-502.

Hook, P.B., Burke, I.C., Lauenroth, W.K., 1991. Heterogeneity of soil and plant $\mathrm{N}$ and $\mathrm{C}$ associated with individual plants and openings in North American shortgrass steppe. Plant Soil 138, 247-256.

Imberger, K.T., Chiu, C.Y., 2001. Spatial changes of soil fungal and bacterial biomass from a sub-alpine coniferous forest to grassland in a humid, sub-tropical region. Biol. Fertil. Soils $33,105-110$.

Ishii, H., Ford, D.E., Boscolo, M.E., Manriquez, A.C., Wilson, M.E., Hinckley, T.M., 2002. Variation in specific needle area of old-growth Douglas-fir in relation to needle age, withincrown position and epicormic shoot production. Tree Physiol. 22, 31-40.

Jakob, E.M., Porter, A.H., Uetz, G.W., 2001. Site fidelity and the costs of movement among territories: an example from colonial web-building spiders. Can. J. Zool. 79, 2094-2100.

Jiang, Z., Hudson, R.J., 1994. Bite characteristics of wapiti (Cervus elaphus) in seasonal Bromus-Poa swards. J. Range Manage. 47, 127-132.

Jonkel, C., 1970. The behaviour of captured North American bears (with comments on bear management and research). Bioscience $21,1145-1147$.

Jordano, P., 2000. Fruits and frugivory. In: Fenner, M. (Ed.), Seeds: The Ecology of Regeneration in Plant Communities, 2nd ed. CAB International, Wallingford, pp. 125-165.

Kajimoto, T., Matsuura, Y., Sofronov, M.A., Volokitina, A.V., Mori, S., Osawa, A., Abaimov, A.P., 1999. Above- and belowground biomass and net primary productivity of a Larix gmelinii stand near Tura, central Siberia. Tree Physiol. 19, 815-822.

Karpov, V.G. (Ed.), 1983. Regulation Factors of Spruce Forest Ecosystems. Nauka, Leningrad, 317 pp. (in Russian). 
Karpukhin, I.P., Dankovtsev, A.G., Kulikov, A.N., Kelbeshekov, B.K., Karpukhin, V.I., Lukashev, N.A., Sedalishev, V.T., 1990. Use ecological mechanisms of regulating population number of the squirrel in game enterprises of Siberia. In: Animal Resources of Siberia. Game Birds and Mammals. Collected Scientific Papers. Nauka (Siberian Branch), Novosibirsk, pp. 139-141 (in Russian).

Kikuzawa, K., Shidei, T., 1967. On the biomass of arthropods of the Japanese red pine forest in the vicinity of Kyoto. Bull. Kyoto Univ. Forests 39, 1-8.

Kirchman, D.L., 1997. Microbial breathing lessons. Nature 385, 121-122.

Kleiber, M., 1932. Body size and metabolism. Hilgardia 6, 315353.

Knouft, J.H., 2002. Regional analysis of body size and population density in stream fish assemblages: testing predictions of the energetic equivalence rule. Can. J. Fish. Aquat. Sci. 59, 13501360.

Komai, Y., 1998. Augmented respiration in a flying insect. J. Exp. Biol. 201, 2359-2366.

Kozhechkin, V.V., 1990. An experience of Moschus moschiferus registration in the "Stolby" Nature Reserve. In: Animal Resources of Siberia. Game Birds and Mammals. Collected Scientific Papers. Nauka (Siberian Branch), Novosibirsk, p. 248 (in Russian).

Kozlov, V.M., 1990. Rationalization of game resource use. In: Animal Resources of Siberia. Game Birds and Mammals. Collected Scientific Papers. Nauka (Siberian Branch), Novosibirsk, pp. 119-122 (in Russian).

Kudaktin, A.N., 1987. Migration of the brown bear on the Caucasus and rational resource use. In: Yudin, B.S. (Ed.), Ecology of Bears. Nauka (Siberian Branch), Novosibirsk, pp. 97-103 (in Russian).

LaBarbera, M., 1989. Analysing body size as a factor in ecology and evolution. Annu. Rev. Ecol. Syst. 20, 97-117.

Laitat, E., Chermanne, B., Portier, B., 2000. Biomass, carbon and nitrogen allocation in open top chambers under ambient and elevated $\mathrm{CO}_{2}$ and in a mixed forest stand. In: Ceulemans, R.J.M., Veroustraete, F., Gond, V., Van Rensbergen, J.B.H.F. (Eds.), Forest Ecosystem Modelling, Upscaling and Remote Sensing. Academic Publishing, The Hague, pp. 33-59.

Lal, R., 1990. Soil erosion and land degradation: the global risks. In: Lal, R., Stewart, B.A. (Eds.), Advances in Soil Science, Soil Degradation, vol. 11. Springer-Verlag, New York, pp. 129172.

Lampert, W., 1989. The adaptive significance of diel vertical migration of zooplankton. Funct. Ecol. 3, 21-27.

Larcher, W., 1980. Ökologie der Pflanzen. UTB Ulmer, Stuttgart.

Lavov, M.A., 1966. Roe deer population on theVitim plateau. In: Problems of Zoology. Materials for the IIIrd Session of the Siberian Zoologists. Tomsk University Press, Tomsk, pp. 206-207 (in Russian).

Lavov, M.A., 1987. Brown bear in Byelorussia. In: Yudin, B.S. (Ed.), Ecology of Bears. Nauka (Siberian Branch), Novosibirsk, pp. 27-34 (in Russian).

Lawton, J.H., 1986. Surface availability and insect community structure: the effects of architecture and fractal dimension of plants. In: Juniper, B.E., Southwood, T.R.E. (Eds.), Insects and the Plant Surface. Edward Arnold, London, pp. 317-331.

Lawton, J.H., 1990. Species richness and population dynamics of animal assemblages. Patterns in body size: abundance space. Phil. Trans. R. Soc. Lond. B 330, 283-291.

Leigh Jr., E.G., 1965. On the relation between the productivity, biomass, diversity, and stability of a community. Proc. Natl. Acad. Sci. U.S.A. 53, 777-783.

Lerat, S., Gauci, R., Catford, J.G., Vierheilig, H., Piché, Y., Lapointe, L., 2002. ${ }^{14} \mathrm{C}$ transfer between the spring ephemeral Erythronium americanum and sugar maple saplings via arbuscular mycorrhizal fungi in natural stands. Oecologia 132, 181-187.

Li, B.-L., Charnov, E.L., 2001. Diversity-stability relationships revisited: scaling rules for biological communities near equilibrium. Ecol. Model. 140, 247-254.

Li, B.-L., Gorshkov, V.G., Makarieva, A.M., 2004. Energy partitioning between differently-sized organisms and ecosystem stability. Ecology, in press.

Li, W.K.W., 2002. Macroecological patterns of phytoplankton in the northwestern North Atlantic Ocean. Nature 419, 154-157.

Lieth, H., 1975. Primary production of the major vegetation units of the world. In: Lieth, H., Whittaker, R. (Eds.), Primary Productivity of the Biosphere. Springer-Verlag, Berlin, pp. 203-215.

Lighton, J.R.B., Brownell, P.H., Joos, B., Turner, R.J., 2001. Low metabolic rate in scorpions: implications for population biomass and cannibalism. J. Exp. Biol. 204, 607-613.

Lighton, J.R.B., Weier, J.A., Feener Jr., D.H., 1993. The energetics of locomotion and load carriage in the desert harvester ant Pogonomyrmex rugosus. J. Exp. Biol. 181, 49-61.

Lin, Q., Brookes, P.C., 1999. An evaluation of the substrateinduced respiration method. Soil Biol. Biochem. 31, 19691983.

Loskutov, A.V., 1987. Peculiarities of bear behaviour in the Bashkir Nature Reserve. In: Yudin, B.S. (Ed.), Ecology of Bears. Nauka (Siberian Branch), Novosibirsk, pp. 139-145 (in Russian).

Lyalin, V.G., 1990. Productivity and yield of the game resources of the $\mathrm{Ob}$ river basin in the Tomsk region. In: Animal Resources of Siberia. Game Birds and Mammals. Collected Scientific Papers. Nauka (Siberian Branch), Novosibirsk, pp. 149-152 (in Russian).

Makarieva, A.M., Gorshkov, V.G., Li, B.-L., 2003. A note on metabolic rate dependence on body size in plants and animals. J. Theor. Biol. 221, 301-307.

Marquet, P.A., Navarrete, S.A., Castilla, J.C., 1990. Scaling population density to body size in rocky intertidal communities. Science 250, 1125-1127.

May, M.L., 1995. Dependence of flight behavior and heat production on air temperature in the green darner dragonfly Anax junius (Odonata: Aeshnidae). J. Exp. Biol. 198, 23852392.

McCann, K.S., 2000. The diversity-stability debate. Nature 405, 228-233.

Mirutenko, M.V., 1990. Distribution of industrially important animal resources in the south of the Krasnoyarsk region and resource exploitation. In: Animal Resources of Siberia. 
Game Birds and Mammals. Collected Scientific Papers. Nauka (Siberian Branch), Novosibirsk, pp. 207-210 (in Russian).

Mitchell, J.E., Pfadt, R.E., 1974. A role of grasshoppers in a shortgrass prairie ecosystem. Environ. Entomol. 3, 358-360.

Moore, J.C., de Ruiter, P.C., Hunt, H.W., 1993. Influence of productivity on the stability of real and model ecosystems. Science 261, 906-908.

Moran, V.C., Southwood, T.R.E., 1982. The guild composition of arthropod communities in trees. J. Anim. Ecol. 51, 289-306.

Mosheva, T.S., 2000. Musk deer. In: Lomanov, K.I. (Ed.), The Resource Status of Game Animals in Russian Federation. Game Animals of Russia (Biology, Conservation, Resource Studies and Rational Use) Series, No. 2-2000. Tsentrokhotkontrol (Department of Conservation and Development of Game Resources Press), Moscow, http://www.aris.ru/MSHP/DEOXO/ SBORNIK/36.html (in Russian).

Morse, D.R., Lawton, J.H., Dodson, M.M., Williamson, M.H., 1985. Fractal geometry of vegetation and the distribution of arthropod body lengths. Nature 314, 731-733.

Morse, D.R., Stork, N.E., Lawton, J.H., 1988. Species number, species abundance and body length relationships of arboreal beetles in Bornean lowland rain forest trees. Ecol. Entomol. $13,25-27$.

Murashov, Y.P., Ustinov, S.K., Komarov, A.V., 1990. Rational exploitation of game animals of the Eastern Siberia. In: Animal Resources of Siberia. Game Birds and Mammals. Collected Scientific Papers. Nauka (Siberian Branch), Novosibirsk, pp. 267-269 (in Russian).

Muthukrishnan, J., Pandian, T.J., 1987. Insecta. In: Pandian, T.J., Vernberg, F.J. (Eds.), Animal Energetics, vol. 1. Protozoa Through Insecta. Academic Press, San Diego, pp. 373-511.

Nagy, K.A., 1987. Field metabolic rate and food requirement scaling in mammals and birds. Ecol. Monogr. 57, 111-128.

Navarrete, S.A., Menge, B.A., 1997. The body size-population density relationship in tropical rocky intertidal communities. J. Anim. Ecol. 66, 557-566.

Nee, S., Read, A.F., Greenwood, J.J.D., Harvey, P.H., 1991. The relationship between abundance and body size in British birds. Nature 351, 312-313.

Odum, E., 1971. Fundamentals of Ecology, 3rd ed. W.B. Saunders Company, Philadelphia, 574 pp.

Ohtonen, R., Väre, H., 1998. Vegetation composition determines microbial activities in a boreal forest. Soil Microb. Ecol. 36, 328-335.

Pavlinov, N.P., 1990. Impact of elks on forest regrowth. In: Animal Resources of Siberia. Game Birds and Mammals. Collected Scientific Papers. Nauka (Siberian Branch), Novosibirsk, pp. 141-142 (in Russian).

Pavlov, M.P., 1987. Brown bear in the taiga of Vyatka region. In: Yudin, B.S. (Ed.), Ecology of Bears. Nauka (Siberian Branch), Novosibirsk, pp. 34-38 (in Russian).

Pennanen, T., Liski, J., Bååth, E., Kitunen, V., Uotila, J., Westman, C.J., Fritze, H., 1999. Structure of the microbial communities in coniferous forest soils in relation to site fertility and stand development stage. Microb. Ecol. 38, 168-179.

Pérez-Barbería, F.J., Gordon, I.J., 2001. Relationships between oral morphology and feeding style in the Ungulata: a phylogenetically controlled evaluation. Proc. R. Soc. Lond. B 268, 1023-1032.

Peters, R.H., Wassenberg, K., 1983. The effect of body size on animal abundance. Oecologia 60, 89-96.

Petrusevich, K., Grodzinsky, V., 1973. The role of herbivorous animals in the ecosystems. Ekologiya 6, 5-17 (in Russian).

Pikunov, D.G., 1987. Studies of population number of bears in the mountainous forests of the Southern Far East. In: Yudin, B.S. (Ed.), Ecology of Bears. Nauka (Siberian Branch), Novosibirsk, pp. 174-184 (in Russian).

Polishchuk, L.V., 1994. Energetic or biomass equivalence rule? Trends Ecol. Evol. 9, 264.

Potapov, R.L., 1990. The Tetraonidae Birds. Leningrad University Press, Leningrad, 240 pp. (in Russian).

Quillin, K.J., 1999. Kinematic scaling of locomotion by hydrostatic animals: ontogeny of peristaltic crawling by the earthworm Lumbricus terrestris. J. Exp. Biol. 202, 661-674.

Quillin, K.J., 2000. Ontogenetic scaling of burrowing forces in the earthworm Lumbricus terrestris. J. Exp. Biol. 203, 2757-2770.

Quintana, X.D., Comín, F.A., Moreno-Amich, R., 2002. Biomasssize spectra in aquatic communities in shallow fluctuating Mediterranean salt marshes (Empordà wetlands). NE Spain J. Plankt. Res. 24, 1149-1161.

Rhoades, C.C., 1997. Single-tree influence on soil properties in agroforestry systems: lessons from natural and savanna ecosystems. Agrofor. Syst. 35, 71-94.

Robinson, J.G., Redford, K.H., 1986. Body size, diet, and population density of neotropical forest mammals. Am. Nat. 128, 665-680.

Rodríguez, J., Tintoré, J., Allen, J.T., Blanco, J.M., Gomis, D., Reul, A., Ruiz, J., Rodríguez, V., Echevarría, F., JiménezGómez, F., 2001. Mesoscale vertical motion and the size structure of phytoplankton in the ocean. Nature 410, 360363.

Rogacheva, E.V., Vakhrushev, A.A., 1983. Fauna and population numbers of birds in the northern taiga of the Yenisei river basin. In: Syroechkovsky, E.E. (Ed.), Animal World of the Yenisei Taiga and Forest-Tundra and Natural Zonation. Nauka, Moscow, pp. 47-106 (in Russian).

Roy, A.C., Paulignan, Y., Farnè, A., Jouffrais, C., Boussaoud, D., 2000. Hand kinematics during reaching and grasping in the macaque monkey. Behav. Brain Res. 117, 75-82.

Rukovsky, N.N., 1987. Some aspects of bear behaviour in the Vologda region. In: Yudin, B.S. (Ed.), Ecology of Bears. Nauka (Siberian Branch), Novosibirsk, pp. 134-139 (in Russian).

Rykov, A.M., 1987. Ecology of the brown bear in central part of the Pinega river basin. In: Yudin, B.S. (Ed.), Ecology of Bears. Nauka (Siberian Branch), Novosibirsk, pp. 76-84 (in Russian).

Salih, N., Andersson, F., 1999. Nutritional status of a Norway spruce stand in SW Sweden in response to compensatory fertilization. Plant Soil 209, 85-100.

Semionov-Tyan-Shansky, O.I., 1982. Mammals of the Murmansk Region. Knijnoje Izd., Murmansk, 176 pp. (in Russian).

Shipley, L.A., Gross, J.E., Spalinger, D.E., Hobbs, N.T., Wunder, B.A., 1994. The scaling of intake rate in mammalian herbivores. Am. Nat. 143, 1055-1082. 
Shtilmark, F.R., 1963. Ecology of the chipmunk (Eutamias sibiricus Laxm.) in cedar forests of Western Sayan. Zool. Zh. 42, 92-102 (in Russian).

Shtilmark, F.R., 1966. Population dynamics of the chipmunk (Eutamias sibiricus Laxm.) in cedar forests of Western Sayan. In: Problems of Zoology. Materials for the IIIrd Session of the Siberian Zoologists. Tomsk University Press, Tomsk, pp. 272-273 (in Russian).

Shubin, N.G., 1990. Resources and resource exploitation of game animals in the oil- and natural gas-rich areas of the Tomsk region. In: Animal Resources of Siberia. Game Birds and Mammals. Collected Scientific Papers. Nauka (Siberian Branch), Novosibirsk, pp. 145-146 (in Russian).

Shvedov, A.P., 1966. The distribution and population number of small mammals in the regions adjacent to Angara and the upper part of Podkamennaya Tunguska rivers. In: Problems of Zoology. Materials for the IIIrd Session of the Siberian Zoologists. Tomsk University Press, Tomsk, pp. 269-270 (in Russian).

Siemann, E., Tilman, D., Haarstad, J., 1999. Abundance, diversity and body size: patterns from a grassland arthropod community. J. Anim. Ecol. 68, 824-835.

Slobodyan, A.A., 1987. Changes of the areal and population number of the brown bear in the Ukrainian Carpathians. In: Yudin, B.S. (Ed.), Ecology of Bears. Nauka (Siberian Branch), Novosibirsk, pp. 12-18 (in Russian).

Smirnov, M.N., Noskov, V.T., Kelberg, G.V., 1987. Ecology and industrial importance of brown bear in the Buryat Autonomous Republic. In: Yudin, B.S. (Ed.), Ecology of Bears. Nauka (Siberian Branch), Novosibirsk, pp. 60-76 (in Russian).

Smith, R.L., 1996. Ecology and Field Biology, 5th ed. Harper Collins, New York, 740 pp.

Sprules, W.G., Munawar, M., 1986. Plankton size spectra in relation to ecosystem productivity, size, and perturbation. Can. J. Fish. Aquat. Sci. 43, 1789-1794.

Stenstrøm, J., Svensson, K., Johansson, M., 2001. Reversible transition between active and dormant microbial states in soil. FEMS Microbiol. Ecol. 36, 93-104.

Stork, N.E., Blackburn, T.M., 1993. Abundance, body size and biomass of arthropods in tropical forest. OIKOS 67, 483-489.

Terakawa, N.I., Ohsawa, N., 1981. On the arboreal arthropods in the Inabu experimental forest of Nagoya University. II. The relationship between body weight and numbers of individuals. Jpn. Forest. (Soc.) Dis. 91, 349-350.

Tikhonov, A.N., 1987. Systematics, biology and ecology of the brown bear of the mountainous regions of the USSR. In: Yudin, B.S. (Ed.), Ecology of Bears. Nauka (Siberian Branch), Novosibirsk, pp. 6-12 (in Russian).

Tsarev, Y.S., 1966. Qualitative estimation of elk and roe deer habitats in the Novosibirsk region. In: Problems of Zoology.
Materials for the IIIrd Session of the Siberian Zoologists. Tomsk University Press, Tomsk, pp. 267-268 (in Russian).

Tsybulin, S.M., 1990. Summer population and distribution of the roe deer in the Northern part of the Altai Mountains. In: Animal Resources of Siberia. Game Birds and Mammals. Collected Scientific Papers. Nauka (Siberian Branch), Novosibirsk, pp. 248-250 (in Russian).

Tucker, V.A., 1970. Energetic cost of locomotion in animals. Comp. Biochem. Physiol. 34, 841-846.

Ungar, E.D., Ravid, N., 1999. Bite horizons and dimensions for cattle grazing herbage to high levels of depletion. Grass Forage Sci. 54, 357-364.

Ustinov, S.K., Dvoryadkin, A.V., 1987. Ecological control and protection of the brown bear in the region of Baikal Lake. In: Yudin, B.S. (Ed.), Ecology of Bears. Nauka (Siberian Branch), Novosibirsk, pp. 103-108 (in Russian).

Van de Koppel, J., Prins, H.H.T., 1998. The importance of herbivore interactions for the dynamics of African savanna woodlands: an hypothesis. J. Trop. Ecol. 14, 565-576.

Vinokurov, V.N., Mordosov, I.I., 1987. Distribution and population number of the brown bear in the Yakut Autonomous Republic. In: Yudin, B.S. (Ed.), Ecology of Bears. Nauka (Siberian Branch), Novosibirsk, pp. 41-45 (in Russian).

Vygodskaya, N.N., Milyukova, I., Varlagin, A., Tatarinov, F., Sogachev, A., Kobak, K.I., Desyatkin, R., Bauer, G., Hollinger, D.Y., Kelliher, F.M., Schulze, E.-D., 1997. Leaf conductance and $\mathrm{CO}_{2}$ assimilation of Larix gmelinii growing in an eastern Siberian boreal forest. Tree Physiol. 17, 607-615.

Wallis de Vries, M.F., 1995. Estimating forage intake and quality in grazing cattle: a reconsideration of the hand-plucking method. J. Range Manage. 48, 370-375.

Whittaker, R.H., Likens, G.E., 1975. The biosphere and man. In: Lieth, H., Whittaker, R. (Eds.), Primary Productivity of the Biosphere. Springer-Verlag, Berlin, pp. 305-328.

Whittaker, R.H., Marks, P.L., 1975. Methods of assessing terrestrial productivity. In: Lieth, H., Whittaker, R. (Eds.), Primary Productivity of the Biosphere. Springer-Verlag, Berlin, pp. 55-118.

Wikelski, M., Carrillo, V., Trillmich, F., 1997. Energy limits to body size in a grazing reptile, the Galapagos marine iguana. Ecology 78, 2204-2217.

Yamamura, K., 2002. Biodiversity and stability of herbivore populations: influences of the spatial sparseness of food plants. Popul. Ecol. 44, 33-40.

Yudin, B.S. (Ed.), 1987. Ecology of Bears. Nauka (Siberian Branch), Novosibirsk (in Russian).

Zhiryakov, V.A., 1987. Relations between the brown bear and wild ungulates in the Zailiisky Alatau region. In: Yudin, B.S. (Ed.), Ecology of Bears. Nauka (Siberian Branch), Novosibirsk, pp. 91-97 (in Russian). 